\title{
SCALE EFFECT ON SHIP RESISTANCE COMPONENTS AND FORM FACTOR
}

\author{
Ali Dogrul ${ }^{1 *}$, Soonseok Song ${ }^{2}$, Yigit Kemal Demirel ${ }^{2}$ \\ ${ }^{1}$ Department of Naval Architecture and Marine Engineering, Yildiz Technical University, Istanbul, Turkey \\ ${ }^{2}$ Department of Naval Architecture, Ocean and Marine Engineering, University of Strathclyde, Glasgow, UK
}

\begin{abstract}
To design eco-friendly ships, the hydrodynamic behaviour of the hull has to be estimated precisely. The first and foremost one is the ship resistance, which is closely related to the energy efficiency of the ship. Different extrapolation methods, based on different assumptions, have been used to predict the full-scale ship resistance from model-scale experiments. In this manner, it is important to understand the scale effect on the individual ship resistance components. In this study, URANS CFD simulations of KCS and KVLCC2 were conducted at different scales. The total resistance components were decomposed into the individual resistance components to investigate the scale effects. The simulation results were compared with full-scale resistance predictions using different extrapolation methods and the rationale of the different compliances between them was investigated. Finally, the hydrodynamic characteristics in different scales were examined.
\end{abstract}

Keywords: CFD, Ship resistance, Scale effect, KCS, KVLCC2, form factor.

\section{Introduction}

Accurate calculation of the hydrodynamic performance of the ship form is critical for the design of an eco-friendly ship. In terms of ship hydrodynamics, the prediction of the total resistance and the resistance components in calm water is the most important stage. At the end of this stage, the effective power of the ship and the main machine power can be estimated. Ship resistance components include viscosity-induced shear resistance and pressure-induced resistance. The pressure resistance component is of great importance in form design and optimization since the displacement and speed is not desired to change.

At this point, due to the rapid use of computational fluid dynamic methods with low computational cost, studies are made about the investigation of the flow field around different types of ships for different model scales. Several approaches are proposed for the estimation of ship hydrodynamics in full-scale. There are several studies about the scale effect on resistance, form factor, nominal wake and self-propulsion characteristics of ships. Besides, some researches are conducted in recent years to examine the effect of scale on the manoeuvring performance of ships. The study of Oh and Kang [1] deals with the flow around HSVA ship for model and full scales. The viscous flow around the ship stern 
was investigated at two different Reynolds numbers. The numerical results of the model ship were compared with the experimental results in terms of non-dimensional pressure coefficient along the hull and the velocity distributions inside the boundary layer. The interaction between the boundary layer and the wake region around the stern was discussed for different scales. The full scale estimates higher velocity and lower wake region. Raven et al. [2] made a study focusing on the numerical evaluation of ship resistance for model and full-scale. They investigated the scale effect on viscous and wave resistance components for Hamburg Test Case (HTC) containership and KVLCC2 tanker. The scale effect on viscous resistance was determined by conducting double body flow analyses. The form factors of both ships were obtained using different friction lines and the results were discussed. Scale effect on wave pattern and wave resistance was observed by doing free-surface analyses. Wave patterns were compared for model and full-scale, wave resistance was computed as the difference between the free-surface and double body analyses for both scales. It is concluded that the scale effect on form factor and viscous resistance depends on the friction line used for model-ship extrapolation. The form factor shows an increase in full-scale when ITTC 57 friction line is used. McKesson and Doctors [3] investigated the effect of scaling on the resistance of surface-effect ship (SES). The authors compared the results for frictional resistance using different friction lines for various Reynolds numbers. The authors also discussed the scaling effect on resistance components such as seal drag, spray drag, and wave resistance. Wang et al. [4] carried out single-phase analyses of a 4000 TEU container ship for calculation of the nominal wakefield at different scales including the full-scale. The relation between the nominal wakefield and the Reynolds number was examined. In addition to this, the effect of the free-surface on axial velocity distribution in the propeller plane was observed by comparing the results with the experimental ones. Uncertainty analysis was made for the numerical grid structure. A detailed comparison of circumferential axial wake fraction was conducted at different scales and an extrapolation method was proposed for the estimation of the nominal wakefield. The paper of Pereira et al. [5] focused on the evaluation of numerical error and uncertainties for the flow analyses of KVLCC2 at model and full-scale. Scale effects were studied in terms of nominal wake fraction and form factor using fourteen turbulence models available in the RANS solver. Instead of numerical validation with the experiments, the modelling errors of the numerical results were compared for different turbulence models. Finally, it was stated that the full-scale solutions show the robustness of the numerical method while the model scale solutions have some modelling errors. Sun et al. [6] investigated the nominal wakefield of a four screw ship by making experiments. CFD analyses are also made for the same ship at different model scales. Thus, the scale effect on the nominal wake was studied. The wakefield of the inside and outside propellers were compared for different model scales. Kazerooni and Seif [7] presented the scale effect on the resistance of a high-speed monohull. Model experiments were carried out with two model scales. Resistance components were presented 
for different velocities and scales. The experimental results were compared with other empirical methods.

Other relevant studies are mainly focused on the scale effect on the form factor. The study of GarcíaGómez [8] is a cornerstone about scale effect on form factor. The author used the experimental results of four ships with geosim models and calculated the form factors of each geosim model with Prohaska [9] method using ITTC'57 [10] and Grigson [11] friction lines. He analyzed the experimental results and focused on the relation between the form factor correlation and scale factor. Fong and Karafiath [12] made a comprehensive study that includes the experimental resistance results of a geosim model for bare hull and fully appended hull. The experimental results were used to calculate the form factor. The form factors and the correlation from model to full-scale were compared with different friction lines and correlation lines for bare and appended hull geosim models. Kouh et al. [13] focused on numerical analyses for investigation of scale effect on form factor solving RANS equations in their study. Four surface vessels (Wigley hull, KVLCC2, DTMB5415, fishing vessel) and two submerged vessels (DTRC4621, torpedo) were analyzed at different Reynolds numbers. A non-dimensional parameter was used for the comparison of different hull forms. The form factors were calculated with double body flow analyses and the relation between form factor and the Reynolds number was discussed. Another important study was made by Min and Kang [14] that is based on the form factor calculation of fullscale ships using correlation lines. The paper questions the concept that the form factor of the model ship is the same as the form factor of the full-scale ship. Geosim models of a container carrier, LNG carrier, and VLCC were investigated experimentally at low Froude numbers and the form factors of each model were calculated applying Prohaska [9] method. A form factor correction factor (FCF) curve was applied and the results were compared for several ship types. Van et al. [15] conducted model tests for KCS and KVLCC2 hull forms using geosim models. ITTC and ATTC friction lines were employed for form factor calculation. CFD analyses were conducted for the geosim models and the importance of friction line in form factor calculation and the relation between the form factor and the Reynolds number were discussed. Also, the nominal wake distribution of KCS and KVLCC2 were presented for different model scales. Ha et al. [16] focused on the relation between the form factor and the Reynolds number. Several geosim models were analyzed by conducting model experiments to suggest a better correlation line for form factor calculation of full-scale ships. The suggested correlation line was compared with other proposed correlation lines [8], [14] by grouping the geosim models into low and high-speed ships.

Castro et al. [17] studied the self-propulsion performance of KCS at full-scale with the direct discretization of the propeller numerically. The self-propulsion point at full-scale was determined using the open water propeller and bare hull resistance data. The same approach for model scale was used 
to determine self-propulsion parameters and ITTC procedure was employed for prediction at full-scale. Within this approach, the scale effect on self-propulsion characteristics was discussed in terms of nominal wake and thrust deduction factors. Finally, it is found that the computations at full-scale show that the propeller operates more efficiently. In the paper of Jin et al. [18], the authors investigated the scale effect on manoeuvring coefficients of KVLCC2 using a RANS solver. Hydrodynamic performance of the hull was observed by conducting static drift and pure sway analyses. The numerical results were compared with the full-scale results and it is found that the model scale overestimates the turbulence wake zone behind the hull.

As demonstrated by the literature, there exist scale effects not only on the resistance components but also on other hydrodynamic characteristics such as form factor and wake fractions. Therefore, understanding the different features of the scale effect on the various hydrodynamic characteristics are important for better predictions of ship resistance. Also, as every different ship has different hydrodynamic features, it is worth investigating the scale effects on different ship types.

To the best of the authors' knowledge, there exists no specific study to investigate the scale effect on the individual resistance components and examine the compatibilities of different extrapolation methods for resistance predictions. Therefore, this study aims to fill this gap by conducting CFD simulations of towed ships with different hull forms in different scales to investigate the scale effect of different resistance components of different ships, and also to evaluate the compatibilities of different extrapolation methods for different ship hulls.

In this study, URANS CFD simulations of KCS and KVLCC2 were conducted at different scales. A verification study was performed to examine the numerical uncertainties of the simulations while a validation study was conducted by comparing the simulation results with experimental data. The total resistance components were decomposed into the individual resistance components and the scale effects were investigated. The simulation results were compared with full-scale resistance predictions based on different extrapolation methods and the rationale of the different compliances between them was discussed. Finally, the hydrodynamic characteristics in different scales were examined.

This paper is organized as follows: Section 1 giving a brief literature review while Section 2 is for the methodology applied in this study. Section 3 presents the verification and validation of the numerical method. The numerical results and comments were given in Section 4. Finally, conclusions were presented in Section 5. 


\section{Methodology}

\subsection{Approach}

The flow diagram in Figure 1 shows the methodology followed in this study in order to calculate the resistance components of KCS and KVLCC2 ships for each scale. After the calculation of the resistance components and the form factor, a comprehensive study was made for the investigation of the velocity field, pressure distribution, and wave pattern.

Free-surface simulations were carried out at design speed. The numerical method was first verified in terms of grid size and time step size. The numerical method was then validated with the available experimental data. Numerical analyses were conducted for three model scales and full-scale. Freesurface simulations were done in order to calculate the frictional resistance and residual resistance. On the other hand, double body simulations were made by neglecting the free-surface effects. Here, the total resistance is considered as equal to the viscous resistance because the wave resistance is neglected. Wave resistance is calculated using the viscous resistance of double body simulations and the total resistance of free-surface simulations. Besides, the form factor was calculated using the resistance components of double body simulations. The resistance components were derived for each scale and the scale effect is discussed. Finally, the scale effect on the velocity field, pressure distribution, and the wave pattern were examined.

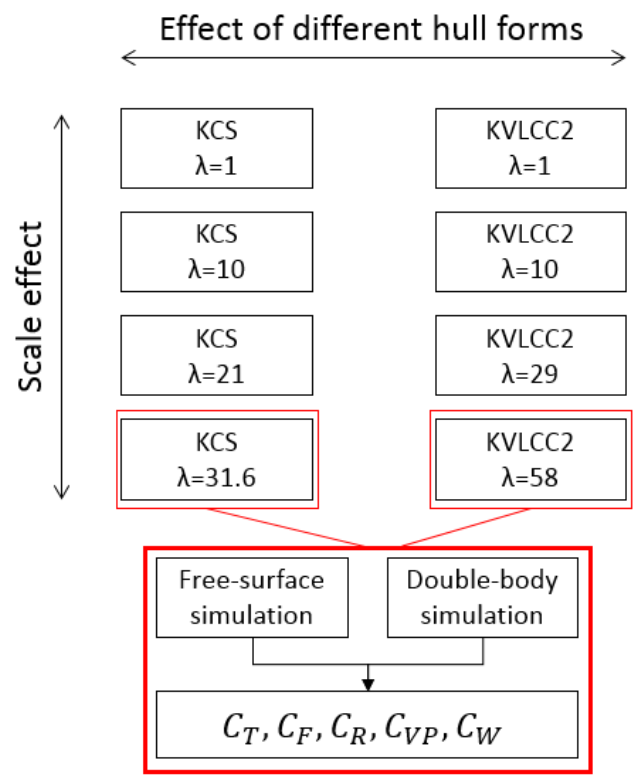

Figure 1. Flow diagram for the calculation of resistance components

For double body approach, where the free-surface is replaced by a symmetry plane, the wave resistance was assumed to be zero because the symmetrical double body is deeply submerged [19]. 


\subsection{URANS Approach}

The numerical analyses were conducted using a commercial CFD software, STAR-CCM+ (version 13.06), which solves unsteady Reynolds-Averaged Navier-Stokes (URANS) equations. The governing equations are the continuity equation and the momentum equations considering the flow is incompressible and turbulent. The continuity equation can be given as:

$\frac{\partial U_{i}}{\partial x_{i}}=0$

Velocity $U_{i}$ can be derived as the mean velocity and the fluctuating velocity components, respectively. $U_{i}=\overline{U_{i}}+u_{i}$

The momentum equations can be written in tensor notation and Cartesian coordinates:

$$
\frac{\partial U_{i}}{\partial t}+\frac{\partial\left(U_{i} U_{j}\right)}{\partial x_{j}}=-\frac{1}{\rho} \frac{\partial P}{\partial x_{i}}+\frac{\partial}{\partial x_{j}}\left[v\left(\frac{\partial U_{i}}{\partial x_{j}}+\frac{\partial U_{j}}{\partial x_{i}}\right)\right]-\frac{\partial \overline{u_{i}^{\prime} u_{j}^{\prime}}}{\partial x_{j}}
$$

Here, $\rho$ is the fluid density, $U_{i}$ is the velocity vector, and $P$ is the pressure. The last two terms belong to the viscous stress tensor while $U$ is the kinematic viscosity.

In accordance with the numerical method, a computational domain was created and discretized using the finite volume method (FVM). The momentum equations are solved using a second-order upwind convection scheme and a first-order temporal discretization. The solution procedure was based on a Semi-Implicit Method for Pressure-Linked Equations (SIMPLE) type algorithm.

The turbulent flow was modelled using the shear stress transport (SST) k- $\omega$ turbulence model. This turbulence model uses a $k-\omega$ formulation inside the boundary layer and a $k-\varepsilon$ formulation in the freestream for a more accurate near-wall treatment, which brings a better prediction in adverse pressure gradients and separating flow [20]-[22].

In addition, for free-surface simulations, the Volume of Fluid (VOF) method was utilized with High Resolution Interface Capturing (HRIC).

\subsection{Geometry and Boundary Conditions}

In this study, two different benchmark hull forms were chosen for the numerical investigation of ship hydrodynamics. The well-known container ship KCS and the very large crude carrier KVLCC2 were analyzed numerically in different model scales and full-scale. The main particulars of the ships are given in Table 1 in full-scale dimensions. Table 2 shows the model scales to be investigated in this study. 
Table 1. Principal particulars of KCS and KVLCC2 in full-scale [23]

\begin{tabular}{|c|c|c|}
\hline Designation & KCS & KVLCC2 \\
\hline Lpp (m) & 230.0 & 320.0 \\
\hline LwL (m) & 232.5 & 325.5 \\
\hline BWL (m) & 32.2 & 58.0 \\
\hline D (m) & 19.0 & 30.0 \\
\hline T (m) & 10.8 & 20.8 \\
\hline WSA w/o rudder $\left(\mathrm{m}^{2}\right)$ & 9498 & 27194 \\
\hline Displacement $\left(\mathrm{m}^{3}\right)$ & 52030 & 312621 \\
\hline $\mathrm{C}_{\mathrm{B}}$ & 0.6505 & 0.8098 \\
\hline $\mathrm{V}_{\mathrm{S}}(\mathrm{knot})$ & 24 & 15.5 \\
\hline Fr & 0.26 & 0.142 \\
\hline
\end{tabular}

Table 2. Model scales of KCS and KVLCC2

\begin{tabular}{|c|c|c|}
\hline Model & Scale factor, $\lambda$ & Length $(\mathrm{m})$ \\
\hline \multirow{4}{*}{ KCS } & 1 & 230 \\
\cline { 2 - 3 } & 10 & 23 \\
\cline { 2 - 3 } & 21 & 10.95 \\
\cline { 2 - 3 } & 31.6 & 7.28 \\
\hline \multirow{3}{*}{ KVLCC2 } & 1 & 320 \\
\cline { 2 - 3 } & 10 & 32 \\
\cline { 2 - 3 } & 29 & 11.03 \\
\cline { 2 - 3 } & 58 & 5.52 \\
\hline
\end{tabular}

Figure 2 and 3 show the dimensions and the boundary conditions of the computational domains of the free-surface simulations of KCS and KVLCC2, respectively. The dimensions were selected in accordance with the ITTC recommendation [24]. The dimensions are kept the same for the double body and freesurface simulations, apart from the absence of the free-surface in the double body simulations. The vertical centre planes were defined as the symmetry plane to minimize the computational cost. For free-surface simulations, the no-slip wall type boundary condition was used on the hull surfaces. The outlets were defined as pressure outlet while the side surfaces are dictated to be symmetry planes. The velocity inlet boundary condition was used for the inlets of the simulations as well as the top and bottom boundaries to simulate the deep water and infinite air assumptions. For double body simulations, the top surface is also defined as the symmetry plane in order to mirror the wetted hull surface. 


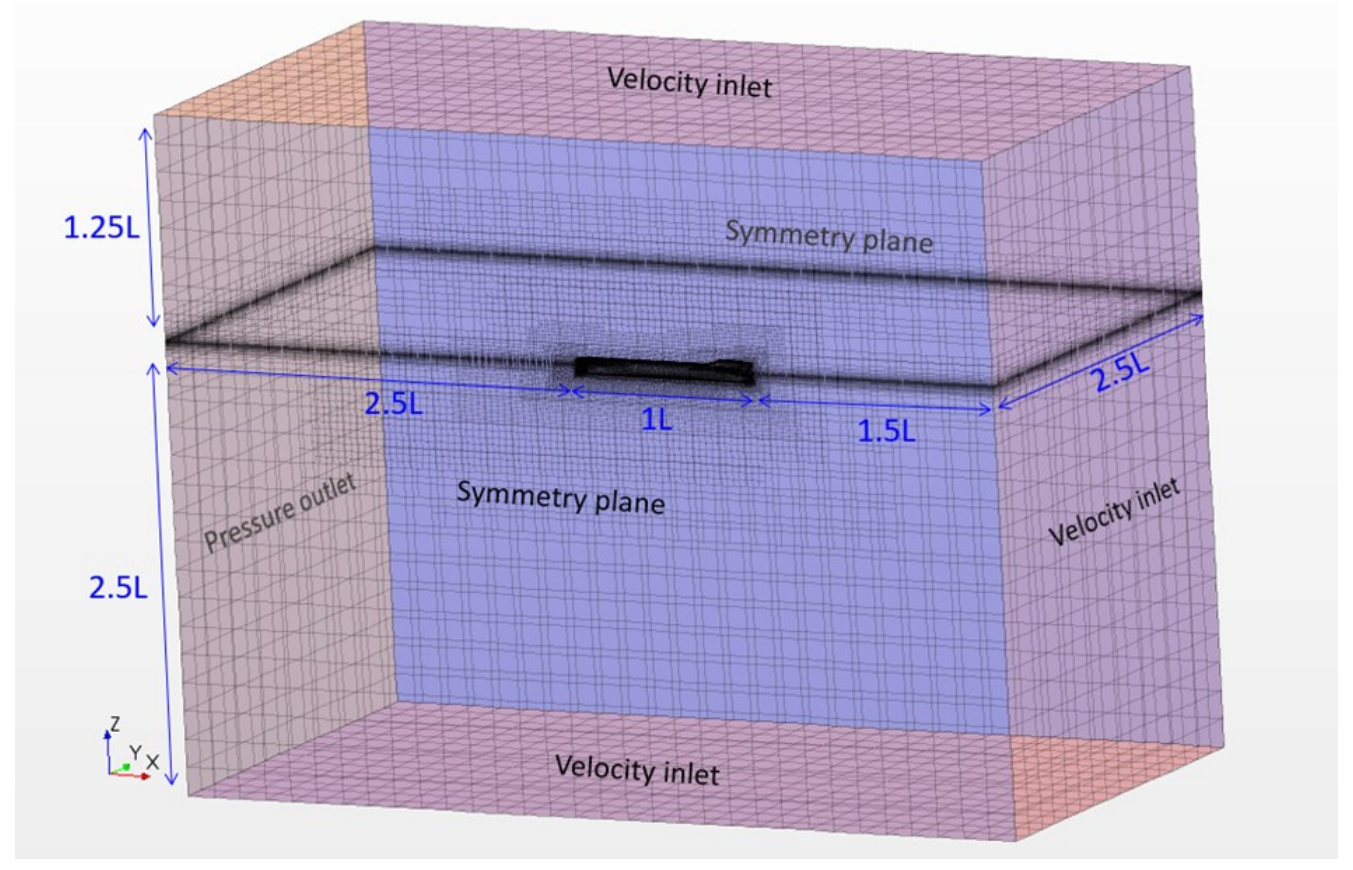

Figure 2. Dimensions of the computational domain for the free-surface simulations of KCS/KVLCC2

\subsection{Mesh Generation}

Trimmer type mesh algorithm was employed for the mesh generation, which is a built-in algorithm of STAR-CCM+. The domain was represented with finite hexahedral elements. Some local mesh refinements were made around the hull, bow and stern, and near the free-surface. Figure 3 shows the volume mesh and the refinements made around the hull and the free-surface. One may also see the denser mesh distribution in the Kelvin wave region and wake region behind the hull. 


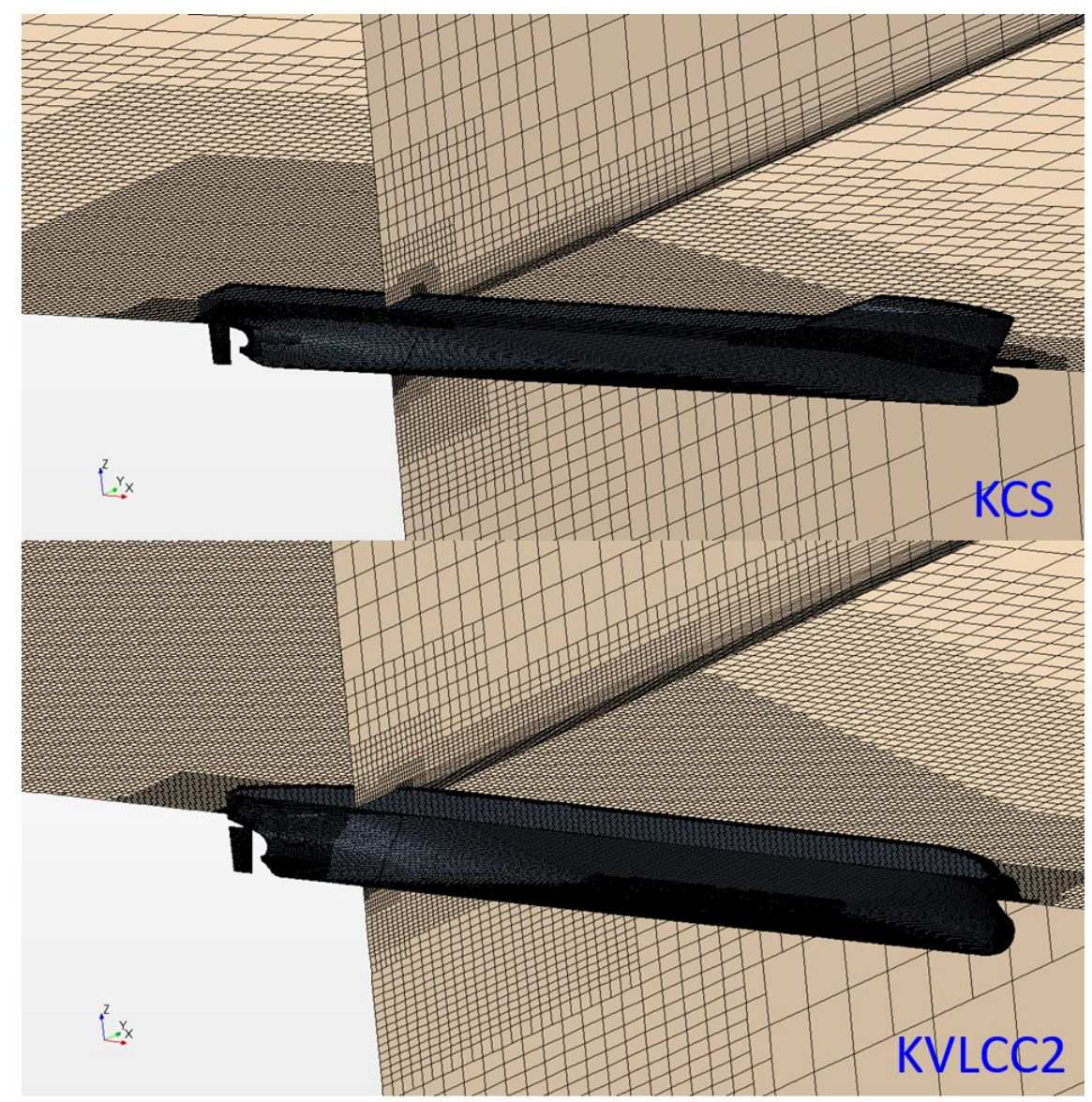

Figure 3. Mesh structure of the computational domain of KCS (upper) and KVLCC2 (lower)

The prism layer mesh was applied near the hull surface as a near-wall refinement and wall $\mathrm{y}^{+}$value was kept between 30 and 300 as suggested by similar numerical studies [25], [26]. Table 3 shows the average wall $\mathrm{y}^{+}$values of the simulations.

Table 3. Parameters used for the calculation of the spatial discretization error

\begin{tabular}{|c|c|c|}
\hline Model & Scale factor, $\lambda$ & Average wall $\mathrm{y}^{+}$value \\
\hline \multirow{4}{*}{ KCS } & 1 & 190 \\
\cline { 2 - 3 } & 10 & 58 \\
\cline { 2 - 3 } & 21 & 43 \\
\cline { 2 - 3 } & 31.6 & 37 \\
\hline \multirow{3}{*}{ KVLCC2 } & 1 & 93 \\
\cline { 2 - 3 } & 10 & 51 \\
\cline { 2 - 3 } & 29 & 45 \\
\hline
\end{tabular}




\section{Verification and Validation}

\subsection{Verification Study}

In order to assess the numerical uncertainties of the CFD models and to determine the sufficient gridspacing and time step, verification studies were performed. The spatial and temporal convergence tests were only conducted for the free-surface simulations and the same grid-spacing and the time steps were used for the double-body simulations. The spatial convergence tests were performed only for the smallest models (i.e. $\lambda=31.6$ for KCS and $\lambda=58$ for KVLCC2), while the temporal convergence tests were conducted for all scales.

The numerical uncertainties originating from the spatial and temporal discretizations were estimated based on the using the Grid Convergence Index (GCI) method [27], as used by similar numerical studies [28]-[33].

According to Celik et al. [27] the apparent order of the method, $p_{a}$, is determined by

$p_{a}=\frac{1}{\ln \left(r_{21}\right)}|\ln | \frac{\varepsilon_{32}}{\varepsilon_{21}}\left|+q\left(p_{a}\right)\right|$

$q\left(p_{a}\right)=\ln \left(\frac{r_{21}^{p_{a}}-s}{r_{32}^{p_{a}}-s}\right)$

$s=\operatorname{sign}\left(\frac{\varepsilon_{32}}{\varepsilon_{21}}\right)$

where, $r_{21}$ and $r_{32}$ are refinement factors given by $r_{21}=\sqrt[3]{N_{1} / N_{2}}$ for a spatial convergence study of a 3D model, or $r \_21=\Delta t \_1 / \Delta t \_2$ for a temporal convergence study. $N$ and $\Delta t$ are the cell number and time step, respectively. $\varepsilon_{32}=\phi_{3}-\phi_{2}, \varepsilon_{21}=\phi_{2}-\phi_{1}$, and $\phi_{k}$ denotes the key variables, i.e. $C_{T}$ in this study.

The extrapolated value is calculated by

$\phi_{\text {ext }}^{21}=\frac{r_{21}^{p} \phi_{1}-\phi_{2}}{r_{21}^{p}-1}$

The approximate relative error, $e_{a}^{21}$, and extrapolated relative error, $e_{\text {ext }}^{21}$, are then obtained by

$e_{a}^{21}=\left|\frac{\phi_{1}-\phi_{2}}{\phi_{1}}\right|$

$e_{\text {ext }}^{21}=\left|\frac{\phi_{e x t}^{21}-\phi_{1}}{\phi_{e x t}^{21}}\right|$

Finally, the fine-grid convergence index is found by

$G C I_{\text {fine }}^{21}=\frac{1.25 e_{a}^{21}}{r_{21}^{p}-1}$

\subsubsection{Spatial convergence study}

Spatial convergence study was performed for the smallest models of $\operatorname{KCS}(\lambda=31.6)$ and $\operatorname{KVLCC2}(\lambda=58)$ with the presence of the free-surface. Three different mesh resolutions were used namely fine, 
medium and coarse meshes with corresponding the cell numbers of $N_{1}, N_{2}$, and $N_{3}$. Table 4 shows the required parameters for the calculation of the spatial discretization error. The total resistance, $R_{T}$, values were used as the key variable. The simulations were conducted at their design speeds (i.e. at the same Froude numbers). As indicated in the table, the numerical uncertainties of $R_{T}$ for KCS and KVLCC2 using the fine meshes are $0.40 \%$ and $0.16 \%$ respectively.

Table 4. Parameters used for the calculation of the spatial discretization error

\begin{tabular}{|c|c|c|}
\hline & $\operatorname{KCS}(\lambda=31.6)$ & $\operatorname{KVLCC2}(\lambda=58)$ \\
\hline$N_{1}$ & $1,279,335$ & $2,877,155$ \\
\hline$N_{2}$ & 690,539 & $1,299,313$ \\
\hline$N_{3}$ & 397,247 & 636,269 \\
\hline$r_{21}$ & 1.23 & 1.30 \\
\hline$r_{32}$ & 1.20 & 1.27 \\
\hline$\Phi_{1}\left(R_{T}\right)$ & 40.781 & 9.340 \\
\hline$\Phi_{2}\left(R_{T}\right)$ & 41.064 & 9.380 \\
\hline$\Phi_{3}\left(R_{T}\right)$ & 41.810 & 9.526 \\
\hline$\varepsilon_{32}$ & $7.46 \mathrm{E}-01$ & $1.46 \mathrm{E}-01$ \\
\hline$\varepsilon_{21}$ & 2.83E-01 & $4.02 \mathrm{E}-02$ \\
\hline$s$ & 1 & 1 \\
\hline$e_{a}^{21}$ & $0.69 \%$ & $0.43 \%$ \\
\hline$q$ & $1.79 \mathrm{E}-01$ & $2.01 \mathrm{E}-01$ \\
\hline$p_{a}$ & $5.59 \mathrm{E}+00$ & $5.62 \mathrm{E}+00$ \\
\hline$\phi_{\text {ext }}^{21}\left(R_{T}\right)$ & 40.650 & 9.328 \\
\hline$e_{e x t}^{21}$ & $0.32 \%$ & $0.13 \%$ \\
\hline$G C I_{\text {fine }}^{21}$ & $0.40 \%$ & $0.16 \%$ \\
\hline
\end{tabular}

\subsubsection{Temporal convergence study}

Temporal convergence studies were performed for the free-surface simulations at each scale. Three different time step resolutions used namely $\Delta \mathrm{t}_{1}, \Delta \mathrm{t}_{2}$, and $\Delta \mathrm{t}_{3}$. Table 5 and 6 show the required parameters for the temporal discretization error calculations of KCS and KVLCC2 simulations respectively. The total resistance, $R_{T}$, values were used as the key variables. The simulations were conducted at their design speeds (i.e. at the same Froude numbers). As indicated in the tables, the 
temporal uncertainties for KCS simulations with the scale factors of $1,10,21$, and 31.6 are $1.47 \%$, $0.35 \%, 0.48 \%$, and $0.90 \%$ respectively. Moreover, the temporal uncertainties for KVLCC2 simulations with the scale factors of $1,10,29$ and 58 are $0.06 \%, 0.26 \%, 0.09 \%$ and $0.17 \%$ respectively.

Table 5. Parameters used for the calculation of the temporal discretization error of the KCS simulations

\begin{tabular}{|c|c|c|c|c|}
\hline & $\mathrm{KCS}(\lambda=1)$ & $\mathrm{KCS}(\lambda=10)$ & $\mathrm{KCS}(\lambda=21)$ & $\mathrm{KCS}(\lambda=31.6)$ \\
\hline$\Delta t_{1}$ & $0.02 \mathrm{~s}$ & $0.01 \mathrm{~s}$ & $0.01 \mathrm{~s}$ & $0.01 \mathrm{~s}$ \\
\hline$\Delta t_{2}$ & $0.04 \mathrm{~s}$ & $0.02 \mathrm{~s}$ & $0.02 \mathrm{~s}$ & $0.02 \mathrm{~s}$ \\
\hline$\Delta t_{3}$ & $0.08 \mathrm{~s}$ & $0.04 \mathrm{~s}$ & $0.04 \mathrm{~s}$ & $0.04 \mathrm{~s}$ \\
\hline$r_{21}, r_{32}$ & 2 & 2 & 2 & 2 \\
\hline$\Phi_{1}$ & $7.6728 \mathrm{E}+05$ & $1.0301 \mathrm{E}+03$ & $1.2753 \mathrm{E}+02$ & $4.0781 \mathrm{E}+01$ \\
\hline$\Phi_{2}$ & $7.7249 \mathrm{E}+05$ & $1.0361 \mathrm{E}+03$ & $1.2847 \mathrm{E}+02$ & $4.1137 \mathrm{E}+01$ \\
\hline$\Phi_{3}$ & $7.8070 \mathrm{E}+05$ & $1.0540 \mathrm{E}+03$ & $1.3119 \mathrm{E}+02$ & $4.1927 \mathrm{E}+01$ \\
\hline$\varepsilon_{32}$ & $8.22 \mathrm{E}+03$ & $1.80 \mathrm{E}+01$ & $2.72 \mathrm{E}+00$ & $7.89 \mathrm{E}-01$ \\
\hline$\varepsilon_{21}$ & $5.21 \mathrm{E}+03$ & $5.91 \mathrm{E}+00$ & $9.35 \mathrm{E}-01$ & $3.56 \mathrm{E}-01$ \\
\hline$e_{a}^{21}$ & $6.785 \mathrm{E}-03$ & $5.736 \mathrm{E}-03$ & $7.330 \mathrm{E}-03$ & $8.732 \mathrm{E}-03$ \\
\hline$p_{a}$ & 0.6586 & 1.6053 & 1.5424 & 1.1487 \\
\hline$\phi_{\text {ext }}^{21}$ & $7.5828 \mathrm{E}+05$ & $1.0273 \mathrm{E}+03$ & $1.2704 \mathrm{E}+02$ & $4.0488 \mathrm{E}+01$ \\
\hline$e_{\text {ext }}^{21}$ & $1.1867 \mathrm{E}-02$ & $2.8163 \mathrm{E}-03$ & $3.8468 \mathrm{E}-03$ & $7.2261 \mathrm{E}-03$ \\
\hline$G C I_{\text {fine }}^{21}$ & $1.47 \%$ & $0.35 \%$ & $0.48 \%$ & $0.90 \%$ \\
\hline
\end{tabular}

Table 6. Parameters used for the calculation of the temporal discretization error of the KVLCC2 simulations

\begin{tabular}{|c|c|c|c|c|}
\hline & KVLCC2 $(\lambda=1)$ & $\operatorname{KVLCC}(\lambda=10)$ & $\operatorname{KVLCC} 2(\lambda=29)$ & $\operatorname{KVLCC}(\lambda=58)$ \\
\hline$\Delta t_{1}$ & $0.02 \mathrm{~s}$ & $0.02 \mathrm{~s}$ & $0.01 \mathrm{~s}$ & $0.01 \mathrm{~s}$ \\
\hline$\Delta t_{2}$ & $0.04 \mathrm{~s}$ & $0.04 \mathrm{~s}$ & $0.02 \mathrm{~s}$ & $0.02 \mathrm{~s}$ \\
\hline$\Delta t_{3}$ & $0.08 \mathrm{~s}$ & $0.08 \mathrm{~s}$ & $0.04 \mathrm{~s}$ & $0.04 \mathrm{~s}$ \\
\hline$r_{21}, r_{32}$ & 2 & 2 & 2 & 2 \\
\hline$\Phi_{1}$ & $7.8801 \mathrm{E}+05$ & $1.2067 \mathrm{E}+03$ & $6.2804 \mathrm{E}+01$ & $9.3396 \mathrm{E}+00$ \\
\hline$\Phi_{2}$ & $7.9029 \mathrm{E}+05$ & $1.2134 \mathrm{E}+03$ & $6.2966 \mathrm{E}+01$ & $9.3805 \mathrm{E}+00$ \\
\hline$\Phi_{3}$ & $7.9061 \mathrm{E}+05$ & $1.2380 \mathrm{E}+03$ & $6.3721 \mathrm{E}+01$ & $9.5545 \mathrm{E}+00$ \\
\hline$\varepsilon_{32}$ & $3.17 \mathrm{E}+02$ & $2.46 \mathrm{E}+01$ & $7.55 \mathrm{E}-01$ & $1.74 \mathrm{E}-01$ \\
\hline$\varepsilon_{21}$ & $2.28 \mathrm{E}+03$ & $6.70 \mathrm{E}+00$ & $1.62 \mathrm{E}-01$ & $4.09 \mathrm{E}-02$ \\
\hline$e_{a}^{21}$ & $2.899 \mathrm{E}-03$ & $5.555 \mathrm{E}-03$ & $2.576 \mathrm{E}-03$ & $4.377 \mathrm{E}-03$ \\
\hline$p_{a}$ & 2.8480 & 1.8770 & 2.2224 & 2.0900 \\
\hline$\phi_{\text {ext }}^{21}$ & $7.8764 \mathrm{E}+05$ & $1.2041 \mathrm{E}+03$ & $6.2760 \mathrm{E}+01$ & $9.3271 \mathrm{E}+00$ \\
\hline$e_{\text {ext }}^{21}$ & $4.6786 \mathrm{E}-04$ & $2.0825 \mathrm{E}-03$ & $7.0297 \mathrm{E}-04$ & $1.3454 \mathrm{E}-03$ \\
\hline
\end{tabular}




\begin{tabular}{|l|l|l|l|l|}
\hline GCI I Ine $_{\text {fine }}^{21}$ & $0.06 \%$ & $0.26 \%$ & $0.09 \%$ & $0.17 \%$ \\
\hline
\end{tabular}

\subsection{Validation Study}

For the validation of the simulation models, free-surface simulations of $\operatorname{KCS}(\lambda=31.6)$ and $\operatorname{KVLCC2}(\lambda=58)$ were compared with the experimental result of Kim et al. [23] using the fine grid and time steps $\left(N_{1}\right.$ and $\left.\Delta t_{1}\right)$ as verified in the previous chapter. Same grid number and time steps for the rest of the analyses as given in Chapter 4. Table 7 compares the total resistance coefficients, $C_{T}$, calculated from the current CFD simulations and the experimental data. As shown in the table, a good agreement was achieved between the CFD and EFD results, showing the relative discrepancies of $-0.3 \%$ and $1.6 \%$ for KCS and KVLCC2 simulations respectively.

Table 7. Parameters used for the calculation of the temporal discretization error of the KCS simulations

\begin{tabular}{|c|c|c|c|}
\hline & $C_{T}$ (present CFD) & $C_{T}$ (EFD, [23]) & Discrepancy \\
\hline $\operatorname{KCS}(\lambda=31.6)$ & $3.544 \mathrm{E}-03$ & $3.556 \mathrm{E}-03$ & $-0.3 \%$ \\
\hline $\operatorname{KVLCC2}(\lambda=58)$ & $4.176 \mathrm{E}-03$ & $4.110 \mathrm{E}-03$ & $1.6 \%$ \\
\hline
\end{tabular}

\section{Results}

\subsection{Double body simulations}

The double body approach dictates that the flow around the underwater body is symmetrical with respect to the undisturbed waterplane [34]. This approach neglects the free-surface effects so that the total resistance of the body is equal to the viscous resistance.

$$
R_{T}=R_{F}+R_{V P}=R_{V}
$$

The resistance components can also be written in non-dimensional form by dividing the resistance by the dynamic pressure force as

$$
\frac{R_{T}}{\frac{1}{2} \rho S V^{2}}=C_{T}=C_{F}+C_{V P}=C_{V}
$$

The form factor can be calculated as the ratio between the viscous resistance, $C_{V}$, and the frictional resistance of a reference friction line, $C_{F_{0}}$, as

$$
1+k=\frac{C_{V}}{C_{F_{0}}}
$$


In this study, the ITTC 1957 friction line and the ATTC 1947 friction line (i.e. Karman-Schoenherr friction line, Shoenherr, 1932) were used to calculate the form factors, $1+k$. These friction lines can be calculated as

$$
\begin{aligned}
& \text { ITTC 1957: } C_{F_{0}}=\frac{0.075}{\left(\log R e_{L}-2\right)^{2}} \\
& \text { ATTC 1947: } \frac{0.242}{\sqrt{C_{F_{0}}}}=\log R e_{L} C_{F_{0}}
\end{aligned}
$$

\subsubsection{Viscous resistance coefficient}

The viscous resistance coefficients of KCS and KVLCC2 models were calculated at different model scales. The ITTC 1957 and ATTC 1947 friction lines are presented together for comparison. As shown in the figure, KVLCC2 has larger viscous resistance coefficients for all Reynolds numbers, which implies larger form factor values.

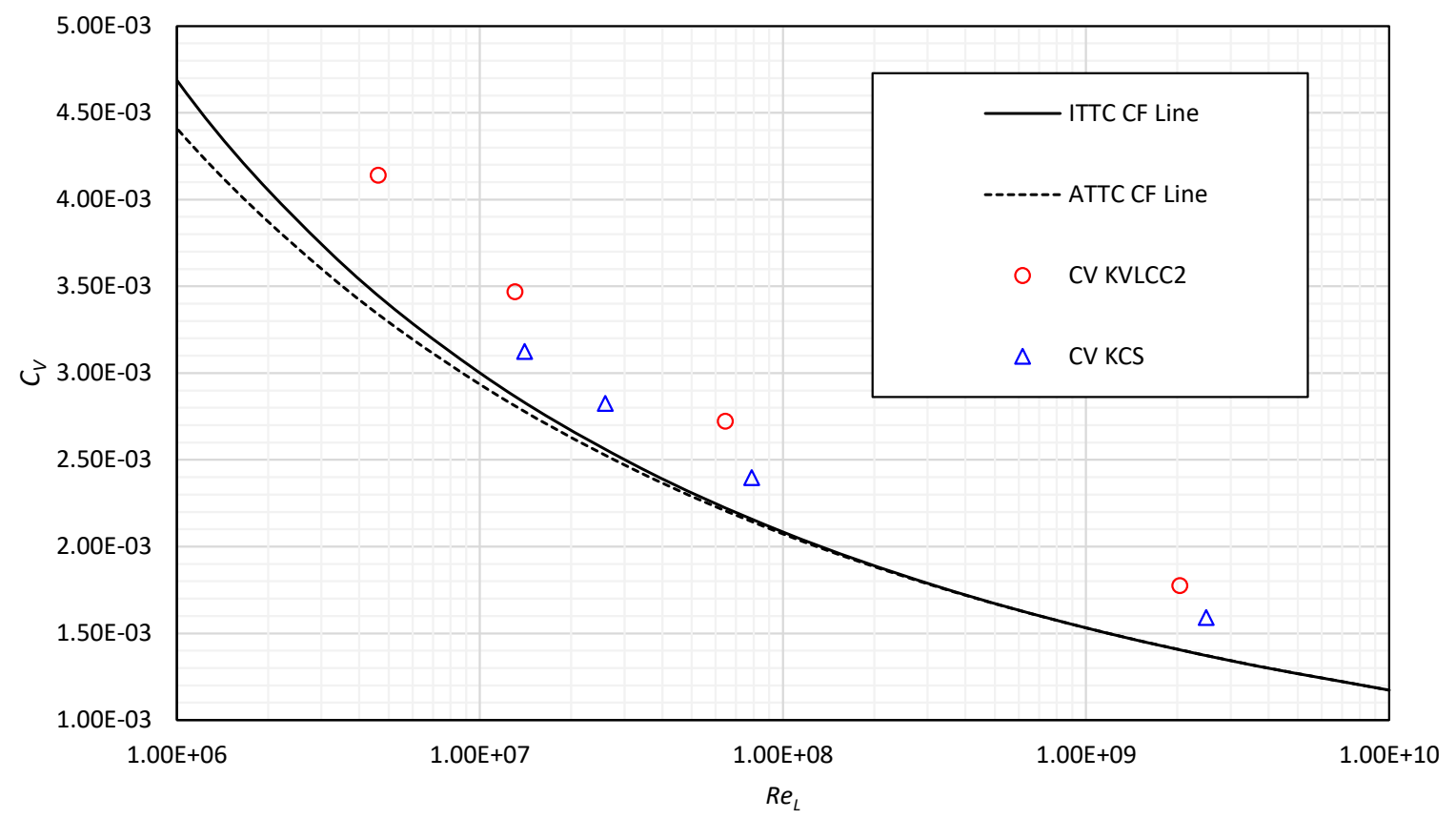

Figure 4. $C_{V}$ values of double body simulations and reference friction lines 


\subsubsection{Form factor}

Figure 5 compares the form factor values, $1+k$, for KCS and KVLCC2 for different model Reynolds numbers including the full-scale. As described above, the $1+k$ values were calculated based on two reference friction lines (ATTC 1947 and ITTC 1957). Due to the differences between the two friction lines, the form factor values showed some differences. Especially for small model lengths (i.e. low Reynolds numbers), the form factor calculation using the ATTC friction line gives larger values for both ship models of KCS and KVLCC2, due to the smaller $C_{F_{0}}$ value of the ATTC curve compared to the ITTC curve at low Reynolds numbers. On the other hand, form factor values collapse on each other at fullscale where ATTC and ITTC $C_{F}$ curves meet.

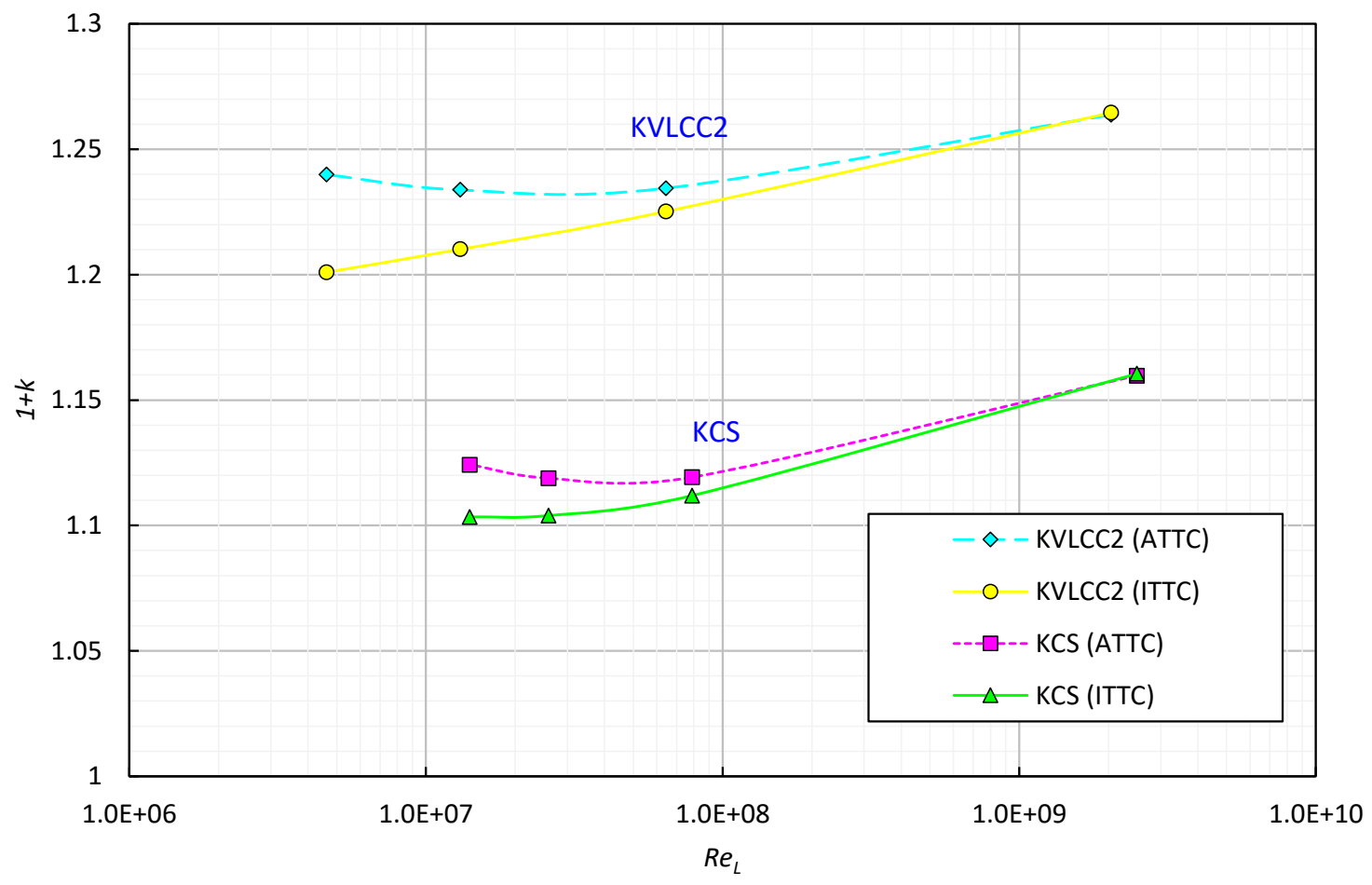

Figure 5. $1+\mathrm{k}$ values based on ITTC and ATTC friction lines 


\subsection{Free-surface simulations}

Free-surface simulations were conducted in order to take the free-surface effects into consideration. Thus, free-surface flow around the ship could be simulated and the wave resistance component is included in the total resistance as

$$
\begin{gathered}
C_{T}=C_{F}+C_{R} \\
C_{R}=C_{V P}+C_{W}
\end{gathered}
$$

The viscous resistance calculated from the double body simulations was used for the estimation of the wave resistance component. The wave resistance coefficient was calculated as

$$
C_{W}=C_{T(\text { free-surface })}-C_{V} \text { (double body) }
$$

The viscous pressure resistance was calculated as

$$
C_{V P}=C_{R}-C_{W}
$$

\subsubsection{Total resistance coefficient}

Figure 6 and 7 show the $C_{T}, C_{F}$, and $C_{R}$ values of KCS and KVLCC2 calculated from the free-surface simulations. The $C_{T}$ values were divided into the $C_{F}$ and $C_{R}$ values by simply decomposing the total drag into the shear and pressure force components. The friction curves of ITTC 1957 and ATTC 1947 are presented together for comparison.

As shown in the figures, the $C_{F}$ values of KCS and KVLCC2, obtained from the simulations, show good agreement with the ITTC 1957 friction line. On the other hand, differences were observed in the $C_{R}$ between KCS and KVLCC2. As shown in Figure 6, the $C_{R}$ values of KCS remain rather stable in all Reynolds numbers while the $C_{R}$ values of KVLCC2 show a decreasing trends as the Reynolds number increases (i.e. ship length increases), as shown in Figure 7. The difference in $C_{R}$ between the two hull forms is discussed in the next section with details. 
KCS

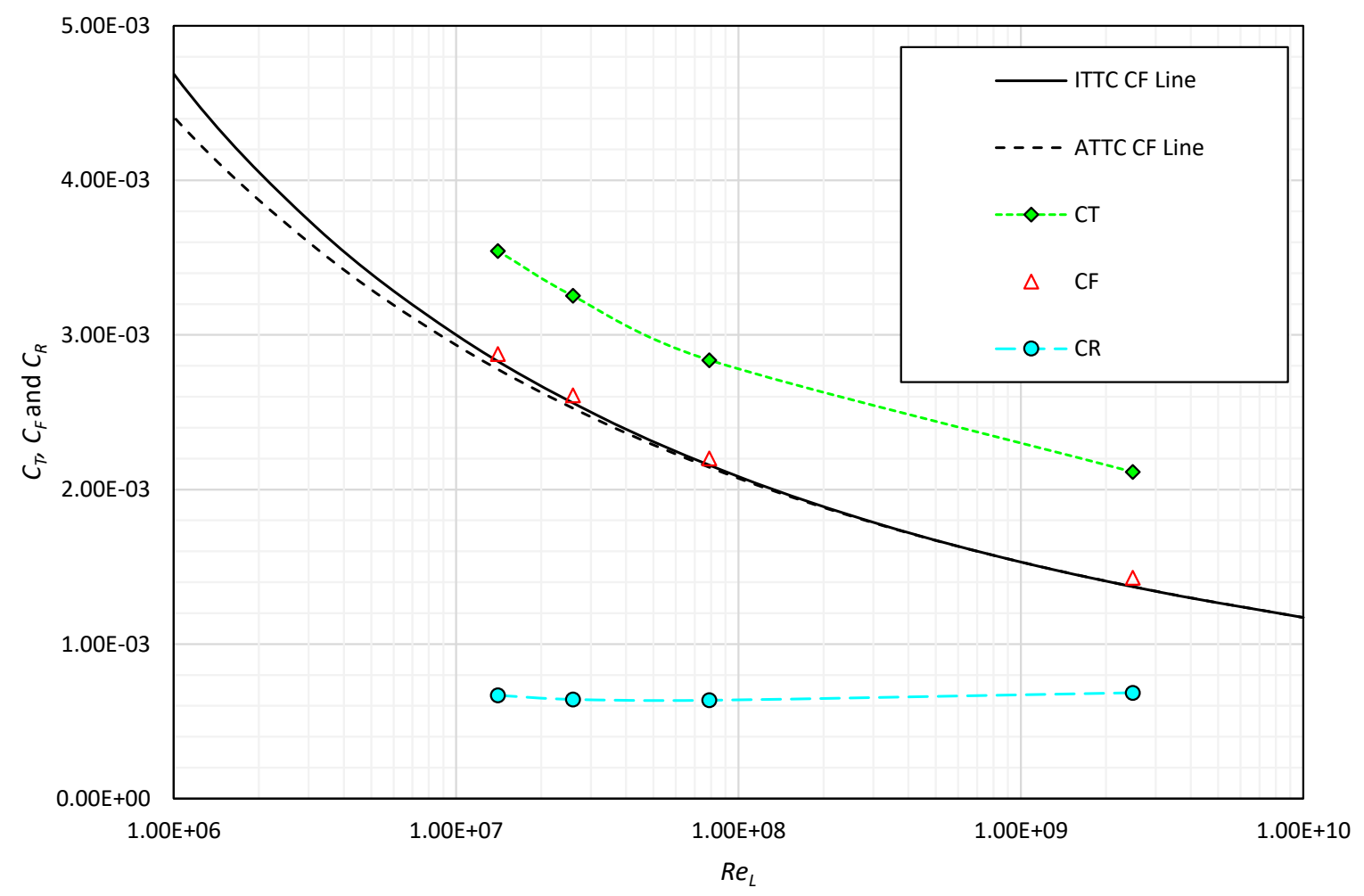

Figure 6. $C_{T}, C_{F}$ and $C_{R}$ coefficients of $K C S$ 


\section{KVLCC2}

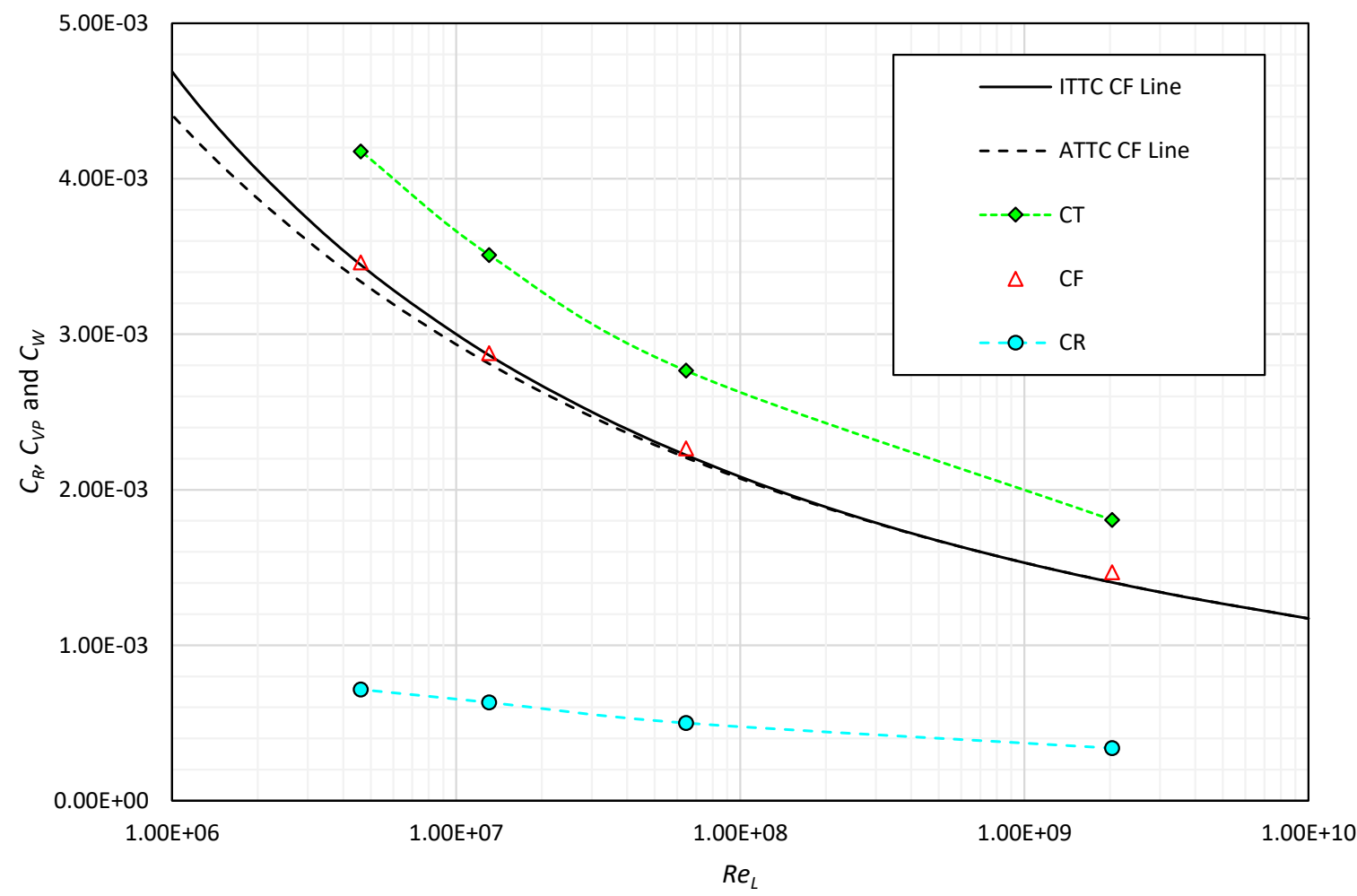

Figure 7. $C_{T}, C_{F}$ and $C_{R}$ coefficients of KVLCC2

\subsubsection{Decomposition of resistance components}

The residual resistance coefficients, $C_{R}$, of KCS and KVLCC2 were decomposed into the viscous pressure resistance, $C_{V P}$, and wave resistance, $C_{W}$, using the equation (18) and (19).

The decomposition of the residual resistance coefficient for KCS is given in Figure 8. As the Reynolds number increases, (i.e. ship length increases,) the wave resistance coefficient, $C_{W}$, increases while the viscous pressure resistance coefficient, $C_{V P}$, decreases. These different trends cancel each other and thus the residual resistance, $C_{R}$, remains rather consistent, while that of KVLCC2 decreases significantly as the ship length increases as shown in Figure 9. This observation implies that the 2D extrapolation based on Froude's hypothesis (i.e. constant $C_{R}$ ) will be more suitable for KCS rather than the 3D extrapolation of Hughes (i.e. constant $C_{W}$ ). 


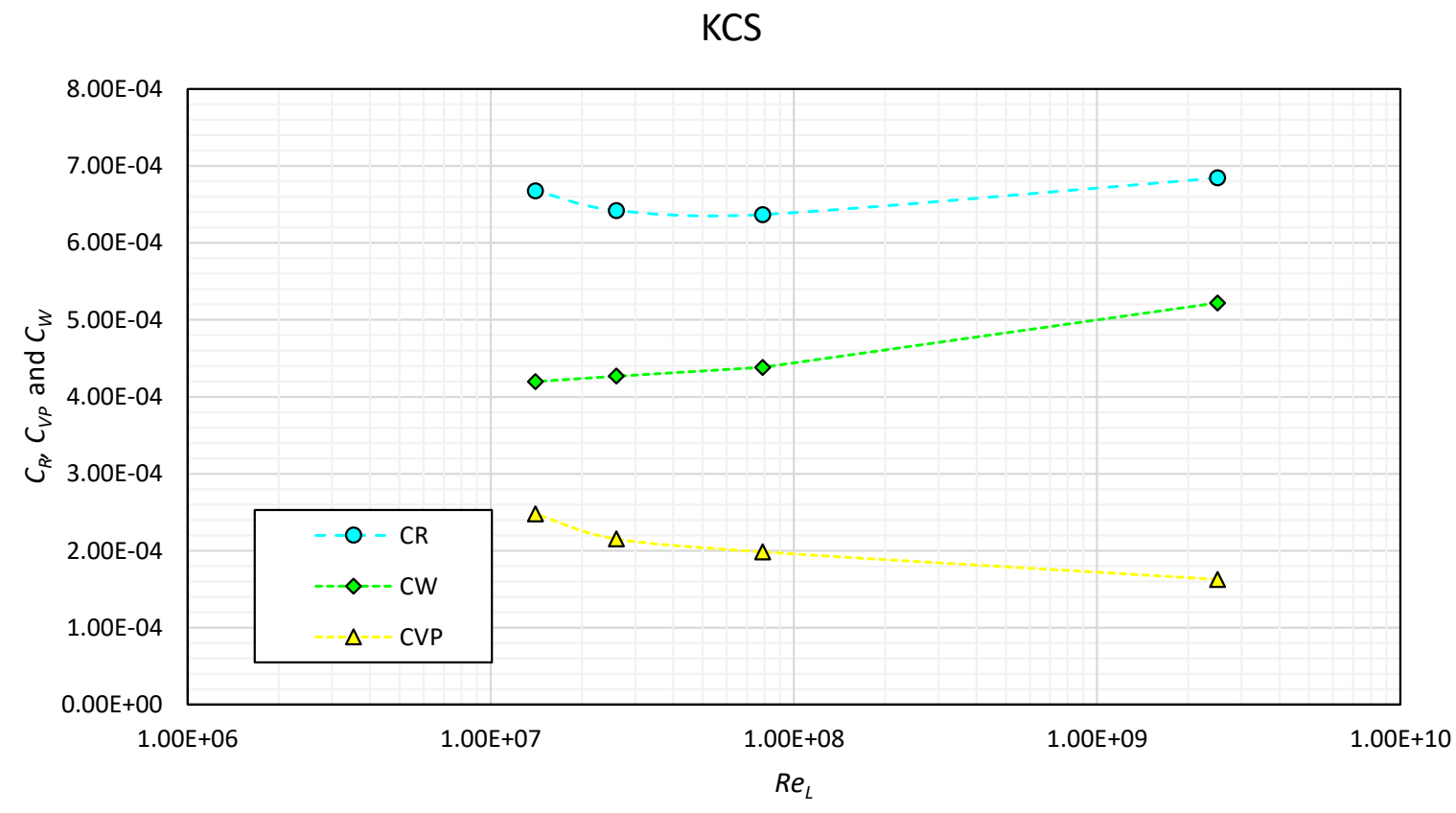

Figure 8. $C_{R}, C_{V P}$ and $C_{W}$ coefficients of KCS

Figure 9 presents the decomposition of the resistance coefficients for KVLCC2. The scale effects of the resistance components of KVLCC2 were observed to be different from the KCS case. The $C_{V P}$ values show a similar decreasing trend, with the Reynolds number (i.e. ship length), while the $C_{w}$ values remain rather stable. This results in a consistently decreasing trend of the $C_{R}$ values, unlike the KCS case. This observation implies that Hughes' 3D extrapolation method is more suitable for KVLCC2 rather than Froude's 2D extrapolation. 
KVLCC2

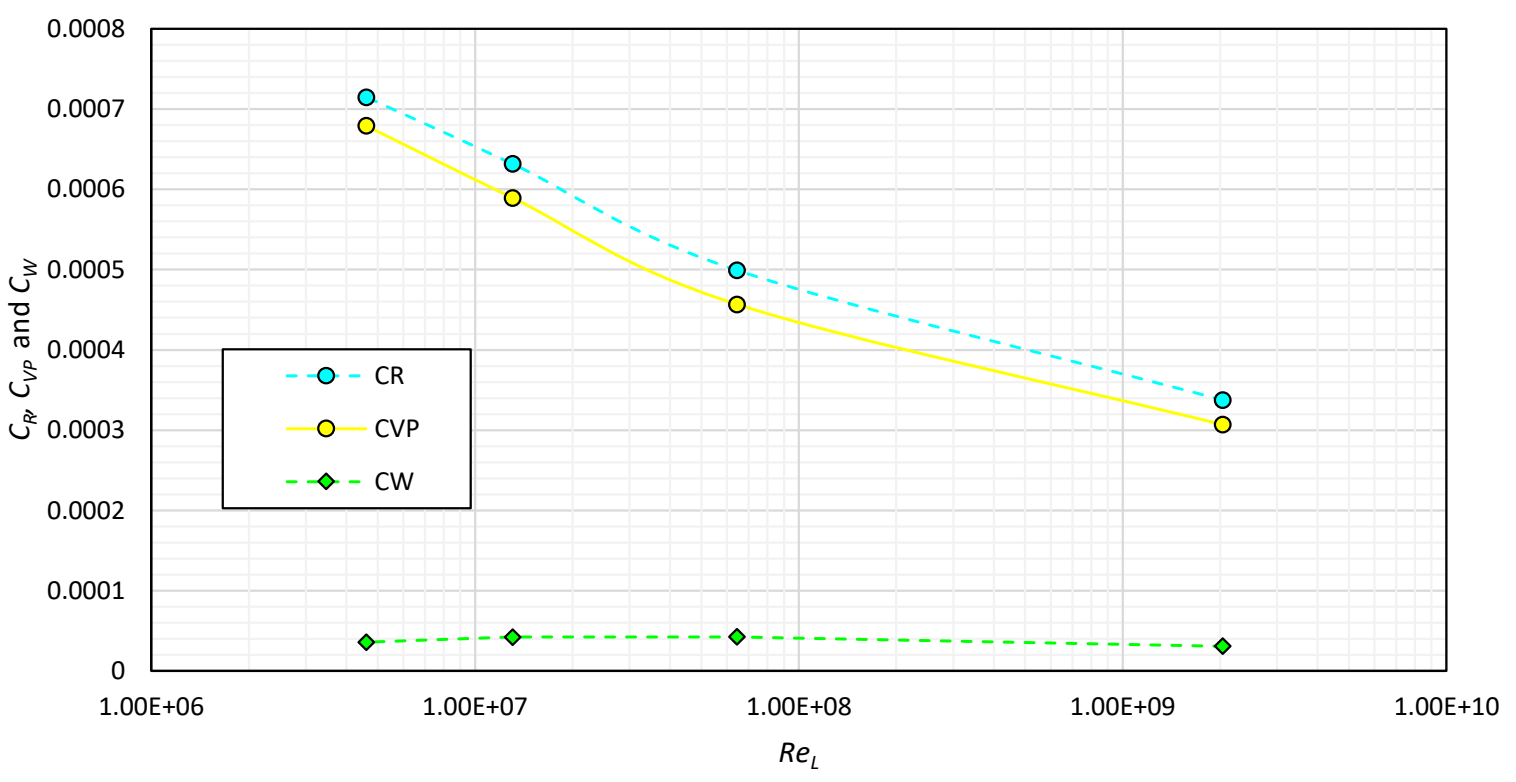

Figure 9. $C_{R}, C_{V P}$ and $C_{W}$ coefficients of KVLCC2

\subsubsection{Contribution of individual resistance components}

After the decomposition of the resistance components, the scale effect on these individual components was investigated for KCS and KVLCC2. The individual resistance components are the frictional resistance $\left(C_{F}\right)$, the viscous pressure resistance $\left(C_{V P}\right)$ and the wave resistance $\left(C_{W}\right)$. The contribution of the individual resistance components to the total resistance was discussed using percentage diagrams. 
KCS

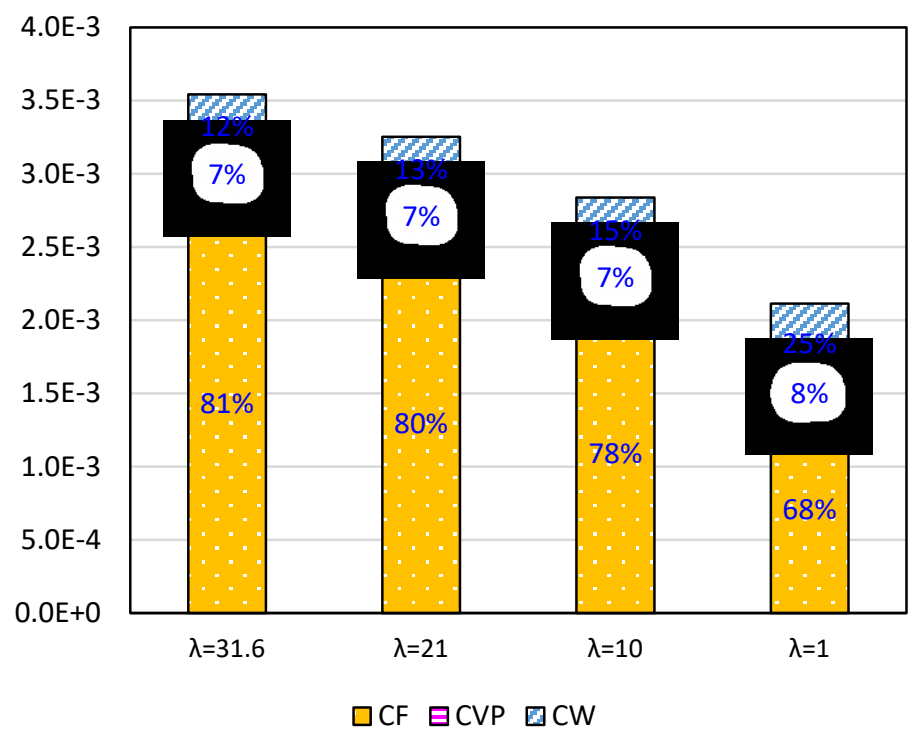

Figure 10. Contribution of individual resistance components for KCS

The contribution of the individual resistance components for KCS at $F r=0.26$ for the different scales is given in Figure 10. It can be seen that the percentage of the viscous pressure resistance is almost the same (7\%) in all model scales. With the increase in model length, the contribution of the frictional resistance decreases from $81 \%$ to $68 \%$ while the wave resistance becomes more significant (from $12 \%$ to $25 \%$ ). In all of the scales, the frictional resistance is the major component.

KVLCC2

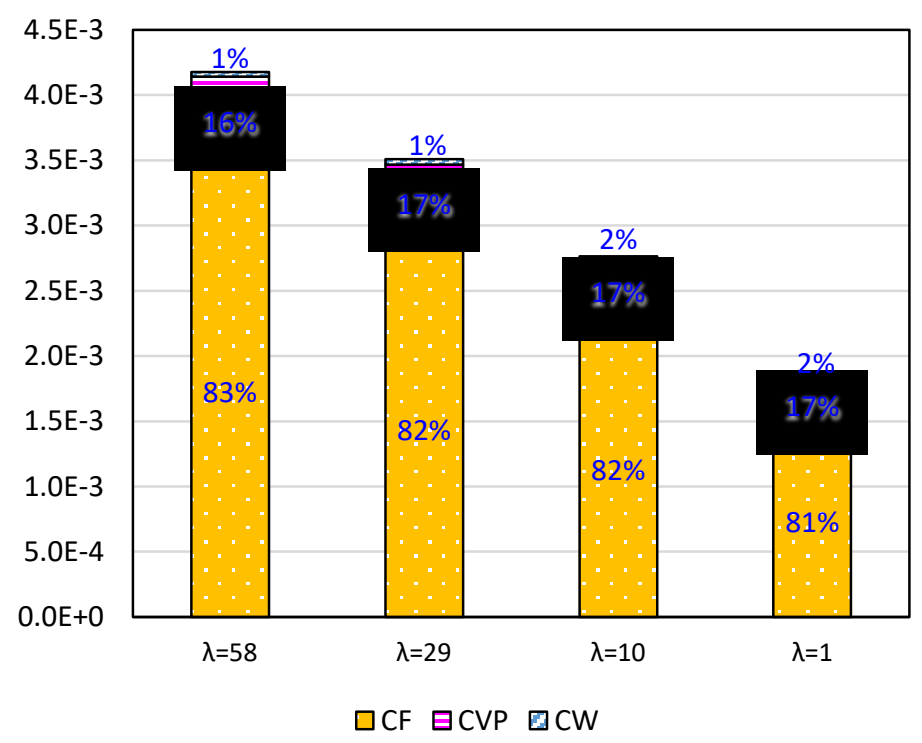

Figure 11. Contribution of individual resistance components for KVLCC2 
Figure 11 compares the contribution of the resistance components for KVLCC2. The wave resistance component has a stable contribution with a small percentage (1-2\%) which can be seen due to the low Froude number $(\mathrm{Fr}=0.142)$. The percentage of the viscous pressure resistance is also consistent with the scales (16-17\%). The major component is the frictional resistance with percentages of $81-83 \%$, which is considerably higher compared to the KCS case.

\subsection{Scale effect on the hydrodynamic characteristics}

In addition to the total resistance and its components, other parameters such as the velocity field, the pressure distribution and the wave pattern were compared for the investigation of scale effects.

\subsubsection{Velocity field}

Figure 12 and 13 show the mean axial velocity contours around the stern of KCS and KVLCC2 at each model scale. The axial velocity was non-dimensionalized with the ship velocity, $V_{S}$ and the contours were obtained from a longitudinal plane located at $y=0.006 L_{P P}$. As shown in the figure, for both KCS and KVLCC2, the relative thickness of the boundary layer compared to the hull size is observed to be thinner for larger vessels. In other words, the boundary layer of smaller vessels is larger due to the lower Reynolds numbers. Similarly, larger wakefields around the stern (i.e. decelerated flow) were observed for smaller vessels, which is also shown in Figure 14.

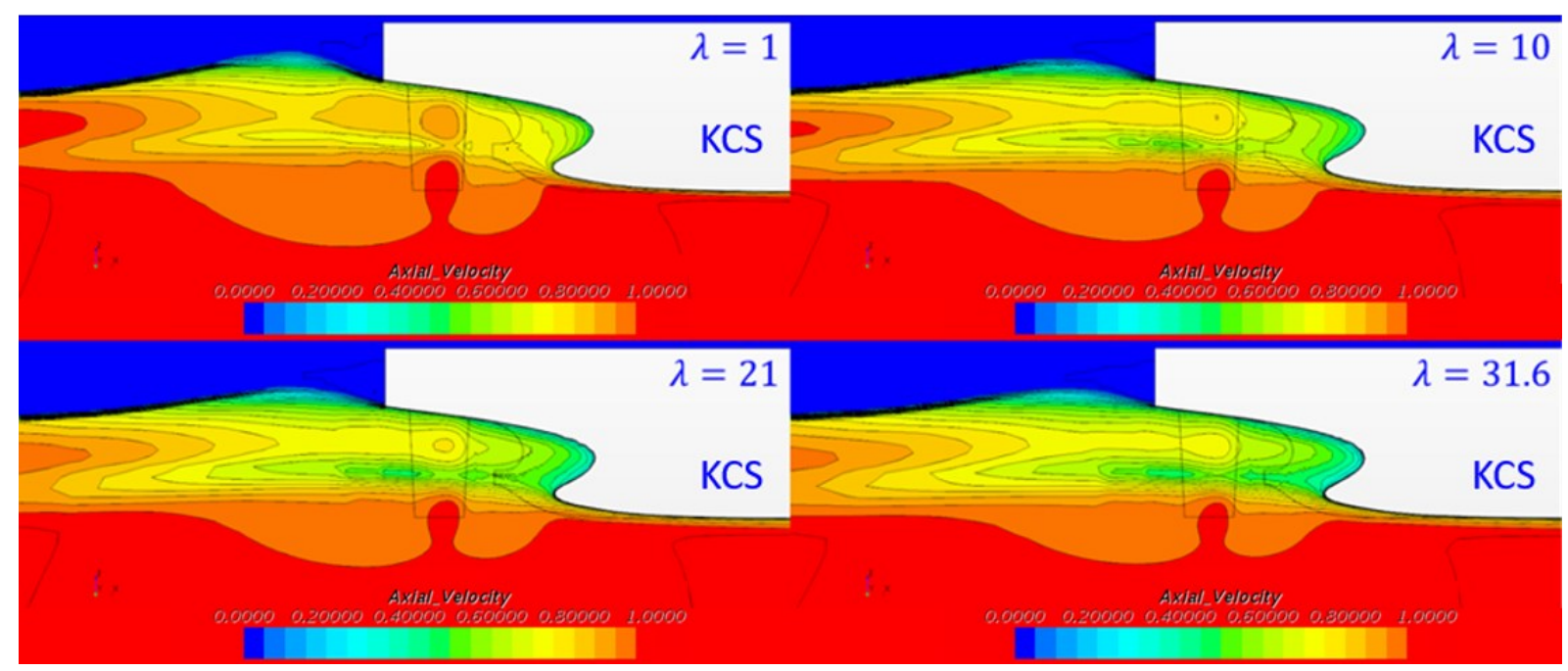

Figure 12. Contours of mean axial velocity $\left(V_{x} / V_{S}\right)$ at $y=0.006 L_{p p}$ of $K C S$ 


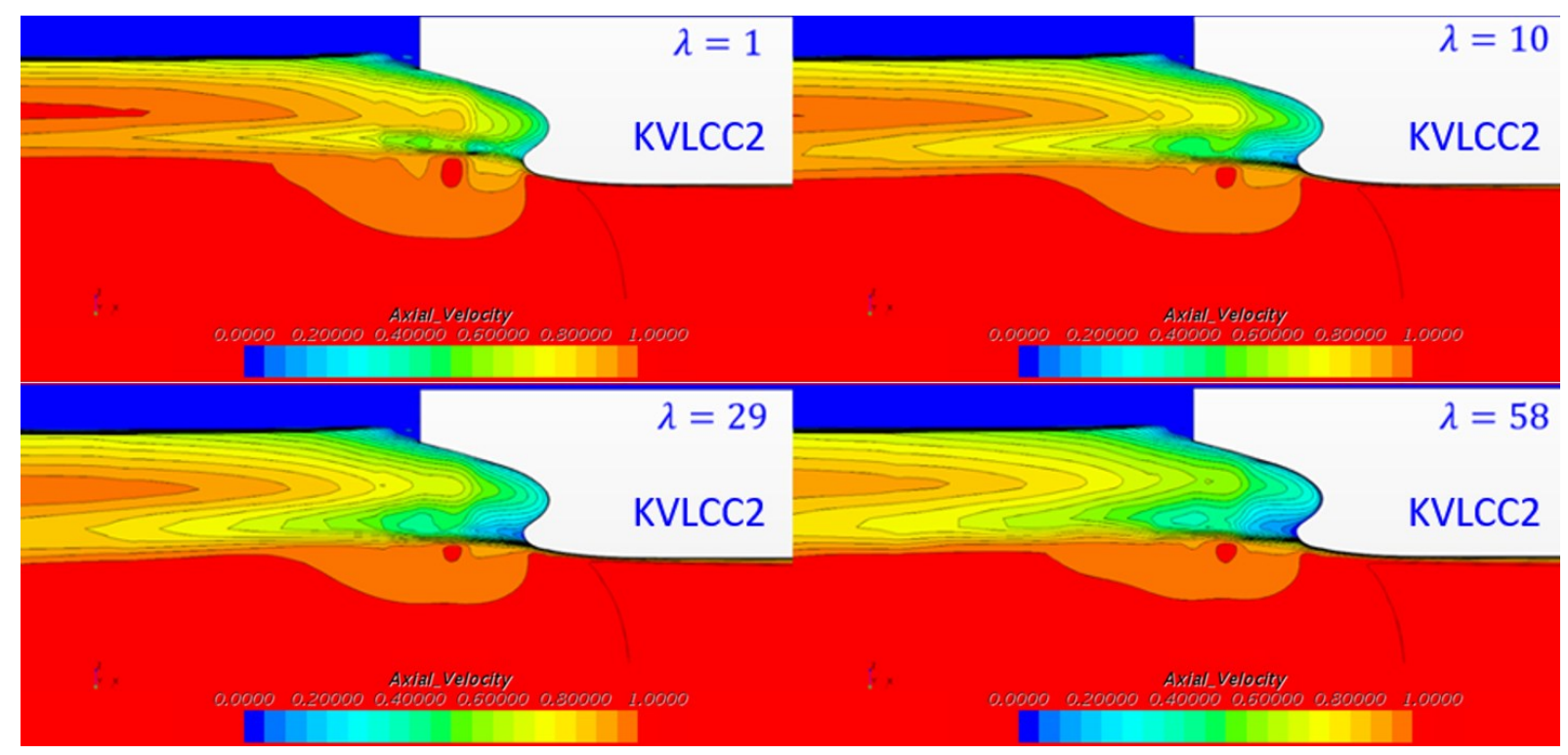

Figure 13. Contours of mean axial velocity $\left(V_{x} / V_{s}\right)$ at $y=0.006 L_{p p}$ of $K V L C C 2$

Contours of the mean axial velocity at the propeller plane $\left(x=0.0175 L_{P P}\right)$ were given in Figure 14 for KCS and KVLCC2 models. As similarly shown in Figure 12 and 13, the wakefield around the hull showed significant dependencies of scale, i.e. the smaller model sizes, the larger wakefields were found due to the lower Reynolds numbers. It is also of note that the KVLCC2 cases show larger wakefields, compared to those of KCS. This can be mostly attributed to the fuller hull shape of KVLCC2 (i.e. larger block coefficient, $C_{B}$ ), which is also related to the larger form factor values of KVLCC2.

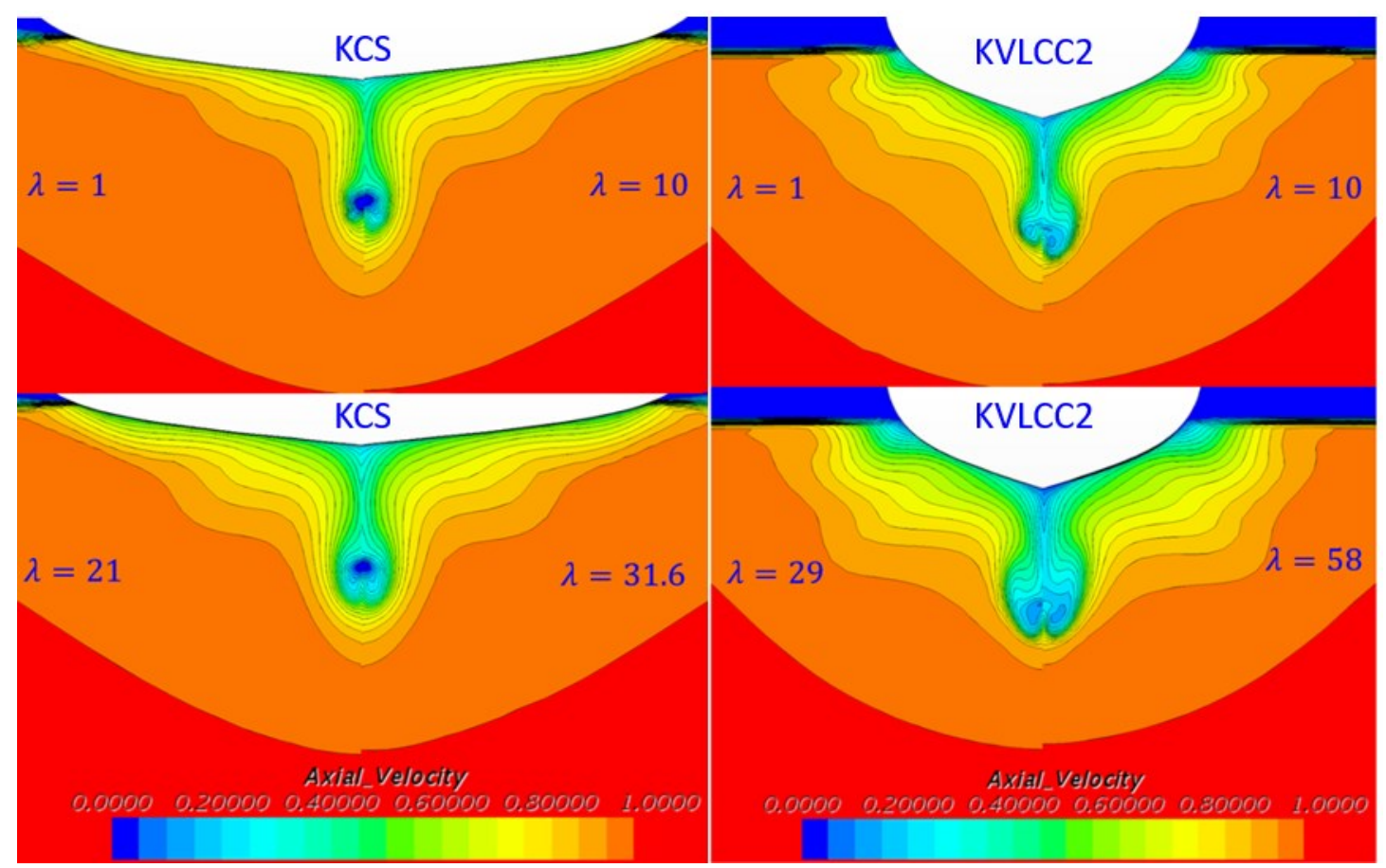

Figure 14. Contours of mean axial velocity $\left(V_{x} / V_{S}\right)$ at $x=0.0175 L_{p p}$ (left: $K C S$, right: $\left.K V L C C 2\right)$ 


\subsubsection{Pressure distribution}

In Figure 15, the dynamic pressure coefficients on the stern of KCS and KVLCC2 models were presented for different model scales. For both vessels, larger pressure recoveries at the stern were observed with smaller scale factors, $\lambda$ (i.e. larger hulls have larger pressure recoveries). This larger pressure recovery can be related to the decreasing trends of the $C_{V P}$ values with Reynolds numbers, shown in Figure 8 and 9.

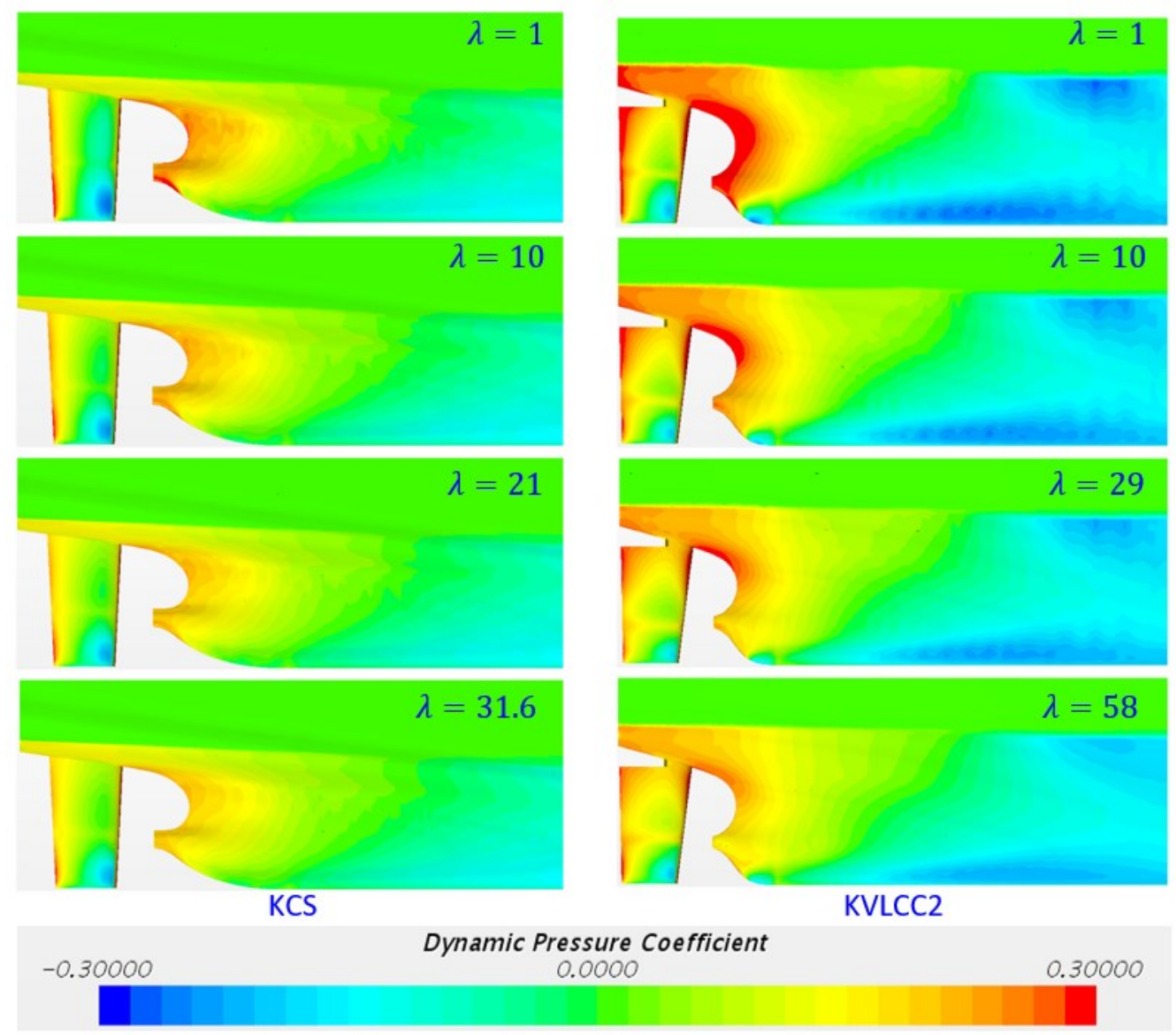

Figure 15. Dynamic pressure coefficient on the stern (left: KCS, right: KVLCC2)

\subsubsection{Wave pattern}

Wave patterns around the hull were compared in each scale for both KCS and KVLCC2 ships in Figure 16 and 17. The wave pattern, in other words, the deformation on the free-surface caused by KCS hull becomes smaller in smaller model lengths in accordance with the wave resistance contribution as given in Figure 8. Higher wave resistance leads to higher wave elevations around the hull. In addition to this, it is observed that the scale effect is particularly observed in the stern wave system while the bow wave system remains almost the same in all scales. 


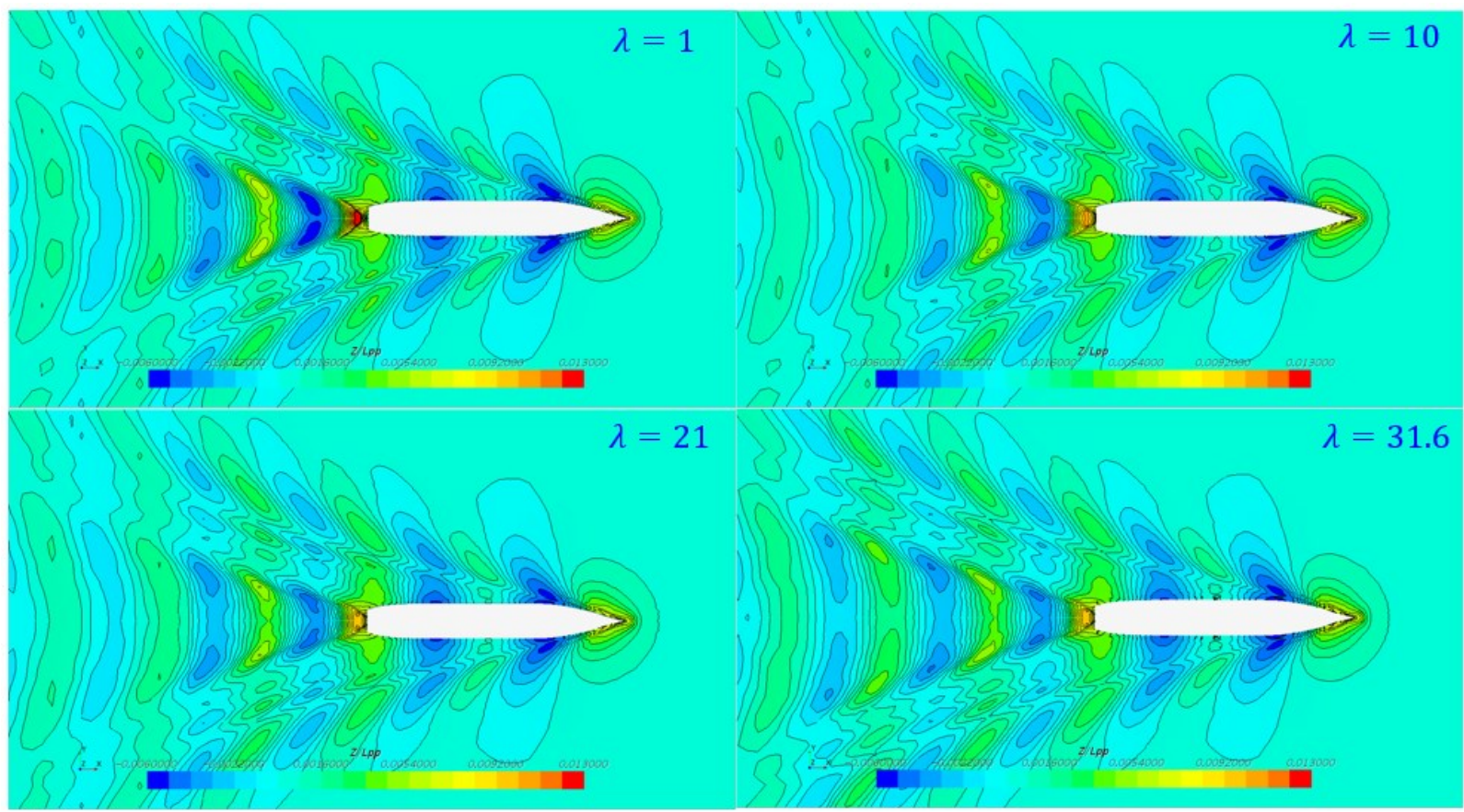

Figure 16. Wave pattern around KCS

However, the difference in the wave pattern around KVLCC2 is minor as the change in wave resistance coefficient was small as given in Figure 9.

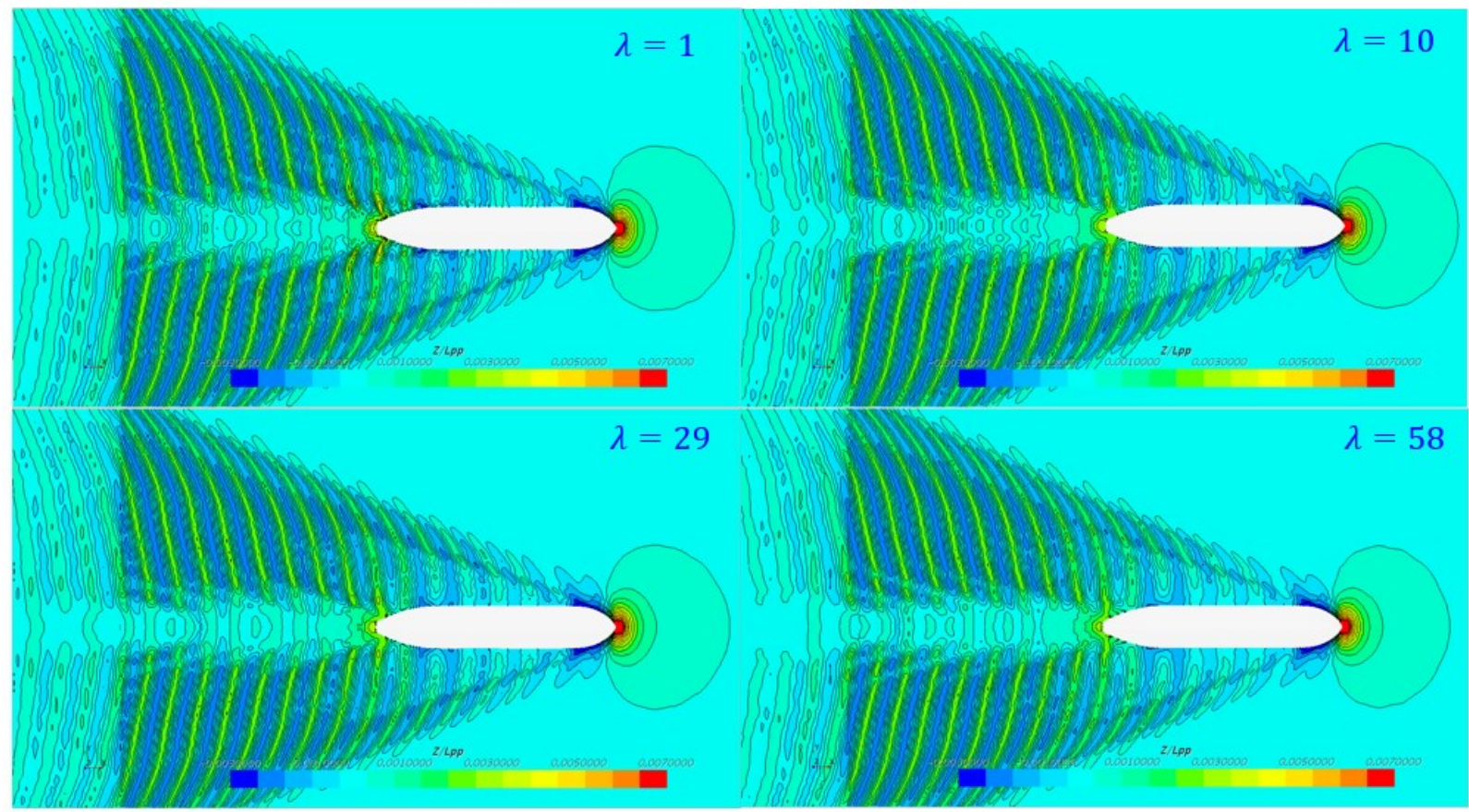

Figure 17. Wave pattern around KVLCC2 


\subsection{Comparison of extrapolation methods}

In Figure 8 and 9, the scale effect of the resistance components was observed to be different for KCS and KVLCC2. KCS showed relatively consistent $C_{R}$ values while $C_{W}$ decreases with the Reynolds number (i.e. ship length). On the other hand, KVLCC2 showed rapidly decreasing $C_{R}$ values, while the $C_{W}$ values remain stable. These different features of the different hull forms imply different compliance of Froude's (constant $C_{R}$ ) and Hughes' (constant $C_{W}$ ) extrapolation methods.

Table 8 shows the total resistance coefficients, $C_{T}$, of KCS and KVLCC extrapolated based on the Froude's extrapolation method, while Table 9 shows the extrapolations based on the Hughes' extrapolation method. For the extrapolations, ITTC 1957 friction line was used rather than using Hughes' friction line for simplicity purposes. The extrapolations were made from the smallest model scale for both KCS and KVLCC2. It is of note that these extrapolation results can differ depending on the choice of the reference friction line (e.g. Grigson's friction line).

As expected, Froude's 2D extrapolation shows better agreement with the full-scale CFD simulation (1.4\%) than Hughes- 3D extrapolation (-8.5\%). Contrarily, KVLCC2 case shows better agreement with Hughes 3D extrapolation than Froude's 2D extrapolation. The rationale of the different features of compliance can be explained more easily with Figure 15, which compares the contributions of the resistance components obtained from the full-scale simulations and the two different extrapolation methods.

As shown in Figure 18, the 3D extrapolation underestimates the $C_{W}$ of KCS compared to the full-scale CFD simulation. This is due to the assumption of the constant $C_{W}$, which is not the case for KCS. For the KVLCC2 case, on the other hand, 2D method overestimates the $C_{T}$ as it does consider the decrease in the $C_{V P}$ at the higher Reynolds number. That means, the assumption of constant $C_{R}$ of Froude's is not valid for KVLCC2.

Table 8. Extrapolation of $C_{T}$ using 2D method

\begin{tabular}{|c|c|c|c|c|c|c|c|}
\hline & $C_{T, m}$ & $C_{F, m}$ & $C_{R}$ & $C_{F, S}$ & $C_{T, s}$ (ext.) & $C_{T, S}$ (CFD) & D \\
\hline KCS & $3.54 \mathrm{E}-03$ & $2.83 \mathrm{E}-03$ & $7.13 \mathrm{E}-04$ & $1.37 \mathrm{E}-03$ & $2.08 \mathrm{E}-03$ & $2.11 \mathrm{E}-03$ & $-1.4 \%$ \\
\hline KVLCC2 & $4.18 \mathrm{E}-03$ & $3.45 \mathrm{E}-03$ & $7.29 \mathrm{E}-04$ & $1.40 \mathrm{E}-03$ & $2.13 \mathrm{E}-03$ & $1.81 \mathrm{E}-03$ & $18.1 \%$ \\
\hline
\end{tabular}

Table 9. Extrapolation of $C_{T}$ using 3D method

\begin{tabular}{|c|c|c|c|c|c|c|c|c|c|c|}
\hline & $C_{T, m}$ & $k$ & $C_{F, m}$ & $C_{V P, m}$ & $C_{W}$ & $C_{F, S}$ & $C_{V P, S}$ & $C_{T, S}$ (ext.) & $C_{T, S}$ (CFD) & $\mathrm{D}$ \\
\hline KCS & $3.54 \mathrm{E}-03$ & 0.103 & $2.83 \mathrm{E}-03$ & $2.91 \mathrm{E}-04$ & $4.22 \mathrm{E}-04$ & $1.37 \mathrm{E}-03$ & $1.41 \mathrm{E}-04$ & $1.93 \mathrm{E}-03$ & $2.11 \mathrm{E}-03$ & $-8.5 \%$ \\
\hline KVLCC2 & $4.18 \mathrm{E}-03$ & 0.201 & $3.45 \mathrm{E}-03$ & $6.93 \mathrm{E}-04$ & $3.57 \mathrm{E}-05$ & $1.40 \mathrm{E}-03$ & $2.82 \mathrm{E}-04$ & $1.72 \mathrm{E}-03$ & $1.81 \mathrm{E}-03$ & $-4.7 \%$ \\
\hline
\end{tabular}


KCS

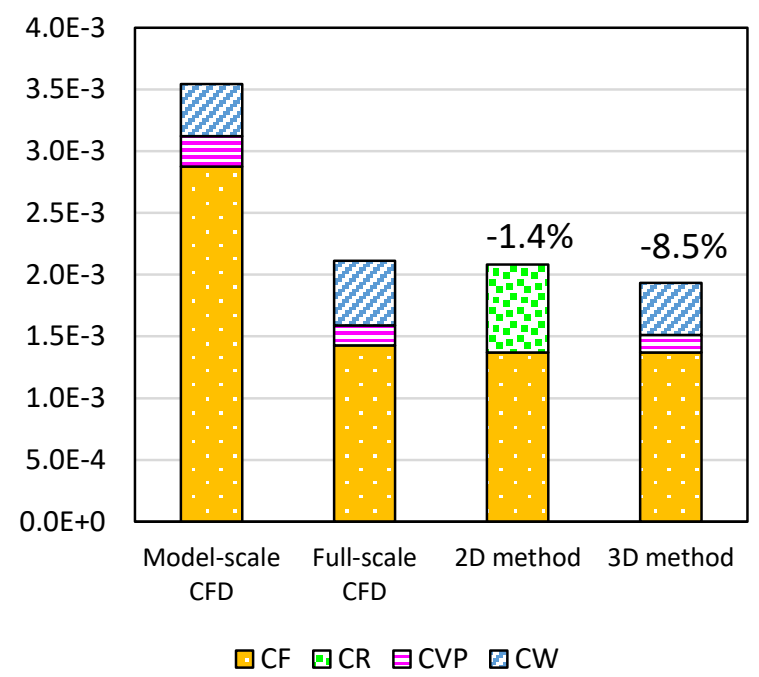

KVLCC2

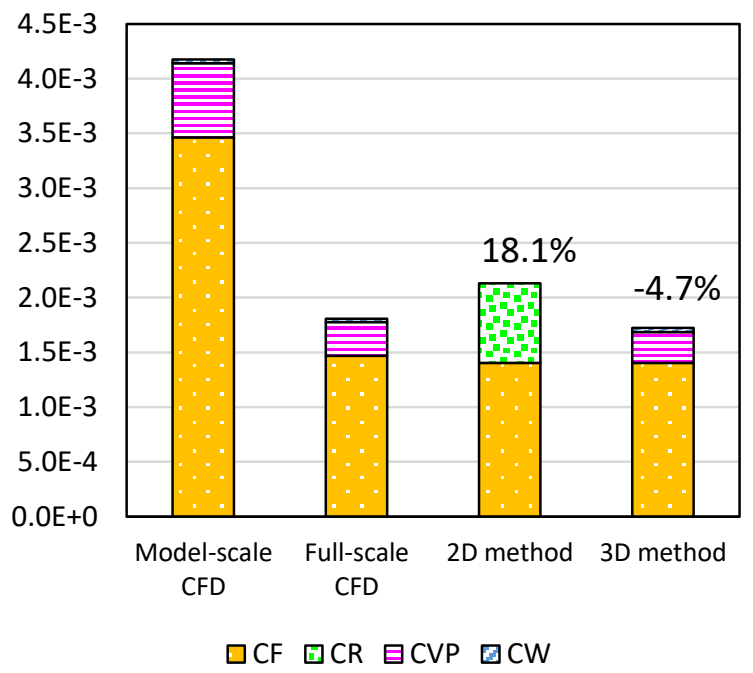

Figure 18. Resistance components from the CFD simulation and the different extrapolation methods for KCS (left) and KVLCC2 (right)

\section{Conclusion}

CFD analyses were carried out to investigate the scale effects on the ship resistance components, form factor, wake field as well as the flow characteristics around the hulls. The analyses were conducted for two different displacement type ships: KCS and KVLCC2. The analyses were made for four scales including the full-scale.

The numerical method was validated with the available experimental data in terms of total resistance. Uncertainty assessment was made for the verification study using the Grid Convergence Index (GCl) method. Spatial and temporal uncertainties were calculated.

Double body simulations were conducted to calculate viscous resistance of the ships by neglecting the free-surface effects and the form factors were determined from the double body simulations. The form factor values were calculated higher for KVLCC2 because of higher viscous resistance.

Free-surface simulations were conducted to calculate the total resistance and resistance components. For KCS, it is observed that the residual resistance coefficient remains nearly the same in all scales while that of KVLCC2 shows a decreasing trend as the Reynolds number increases. This is due to the different scale effects between the viscous pressure resistance and wave resistance and their different contributions for KCS and KVLCC2.

The scale effects on the flow characteristics around the hull were also examined. For both vessels, thinner boundary layers and smaller stern wakes were observed for larger vessels. The larger pressure recoveries at the stern were observed for larger vessels which is in correspondence with the scale effect of the viscous pressure resistance. Differences in the scale effects of wave pattern were 
observed between KCS and KVLCC2. The free-surface elevations around the KVLCC2 hulls in different scales showed almost no scale effect while those of KCS showed significant scale effects, similarly to the scale effect on the wave resistance coefficients.

Finally, the total resistance components calculated based on different extrapolation methods (Froude's and Hughes'), were compared with the full-scale simulation results, in order to examine the compliance of the different extrapolation methods for different ship hulls. Froude's 2D extrapolation method shows a better agreement with the full-scale KCS CFD simulation than Hughes' 3D extrapolation method. Contrarily, for Hughes' 3D method showed a better agreement for KVLCC2 than the 2D method. These differences can be explained by the different scaling effects on the residual resistance and the wave resistance of the different hulls.

\section{Acknowledgements}

The results were obtained using the ARCHIE-WeSt High Performance Computer (www.archiewest.ac.uk) based at the University of Strathclyde.

\section{References}

[1] K.-J. Oh and S.-H. Kang, "Full scale Reynolds number effects for the viscous flow around the ship stern," Comput. Mech., vol. 9, no. 2, pp. 85-94, Mar. 1992, doi: 10.1007/BF00370064.

[2] H. C. Raven, A. van der Ploeg, and A. R. Starke, "Towards a CFD-based prediction of ship performance-progress in predicting full scale resistance and scale effects," Int. J. Marit. Eng., vol. 150, no. A4, 2008.

[3] C. B. McKesson and L. J. Doctors, "Scaling of Resistance From Surface-Effect Ship Model Tests," J. Ship Prod. Des., vol. 29, no. 2, May 2013.

[4] Z.-Z. Wang, Y. Xiong, R. Wang, X.-R. Shen, and C.-H. Zhong, "Numerical study on scale effect of nominal wake of single screw ship," Ocean Eng., vol. 104, pp. 437-451, Aug. 2015, doi: 10.1016/j.oceaneng.2015.05.029.

[5] F. S. Pereira, L. Eça, and G. Vaz, "Verification and Validation exercises for the flow around the KVLCC2 tanker at model and full-scale Reynolds numbers," Ocean Eng., vol. 129, pp. 133-148, Jan. 2017, doi: 10.1016/j.oceaneng.2016.11.005.

[6] S. Sun, X. Chang, C. Guo, H. Zhang, and C. Wang, "Numerical investigation of scale effect of nominal wake of four-screw ship," Ocean Eng., vol. 183, pp. 208-223, Jul. 2019, doi: 10.1016/j.oceaneng.2019.04.032.

[7] M. Fathi Kazerooni and M. S. Seif, "On the scale effects of resistance model tests of high-speed monohulls," J. Braz. Soc. Mech. Sci. Eng., vol. 41, no. 4, p. 200, Apr. 2019, doi: 10.1007/s40430019-1695-x.

[8] A. García-Gómez, "On the form factor scale effect," Ocean Eng., vol. 27, no. 1, pp. 97-109, 2000, doi: 10.1016/S0029-8018(98)00042-0.

[9] C. W. Prohaska, "A simple method for the evolution of the form factor and low speed wave resistance," presented at the Proceedings of 11th ITTC, Tokyo, Japan, 1966, pp. 65-66.

[10] ITTC, "Report of Resistance Committee," presented at the Proceedings of 8th ITTC, Madrid, 1957.

[11] C. W. Grigson, "An Accurate Smooth Friction Line for Use in Performance Prediction," Trans. RINA, vol. 135, pp. 149-162, 1993. 
[12] D. Fong and G. Karafiath, "The Effect of Model Size on Form Factor and Predicted Resistance," presented at the Twenty-Eighth American Towing Tank Conference, Ann Arbor, Michigan, USA, 2007.

[13] J.-S. Kouh, Y.-J. Chen, and S.-W. Chau, "Numerical study on scale effect of form factor," Ocean Eng., vol. 36, no. 5, pp. 403-413, 2009, doi: 10.1016/j.oceaneng.2009.01.011.

[14] K.-S. Min and S.-H. Kang, "Study on the form factor and full-scale ship resistance prediction method," J. Mar. Sci. Technol., vol. 15, no. 2, pp. 108-118, 2010, doi: 10.1007/s00773-009-0077$y$.

[15] S. Van et al., "Resistance characteristics and form factor evaluation for geosim models of KVLCC2 and KCS," in Proceeding of 2nd International Conference on Advanced Model Measurement Technology for EU Maritime Industry, Newcastle upon Tyne, UK., 2011, pp. 282-293.

[16] Y.-J. Ha, Y.-G. Lee, and B. H. Kang, "A Study on the Estimation of the Form Factor of Full-Scale Ship by the Experimental Data of Geosim Models," J. Soc. Nav. Archit. Korea, vol. 50, no. 5, pp. 291-297, 2013, doi: 10.3744/SNAK.2013.50.5.291.

[17] A. M. Castro, P. M. Carrica, and F. Stern, "Full scale self-propulsion computations using discretized propeller for the KRISO container ship KCS," Comput. Fluids, vol. 51, no. 1, pp. 35-47, Dec. 2011, doi: 10.1016/j.compfluid.2011.07.005.

[18] Y. Jin, J. Duffy, S. Chai, C. Chin, and N. Bose, "URANS study of scale effects on hydrodynamic manoeuvring coefficients of KVLCC2," Ocean Eng., vol. 118, pp. 93-106, May 2016, doi: 10.1016/j.oceaneng.2016.03.022.

[19] V. Bertram, Practical Ship Hydrodynamics, 2nd ed. Elsevier Science, 2014.

[20] C. D. Argyropoulos and N. C. Markatos, "Recent advances on the numerical modelling of turbulent flows," Appl. Math. Model., vol. 39, no. 2, pp. 693-732, Jan. 2015, doi: 10.1016/j.apm.2014.07.001.

[21] F. R. Menter, "Two-equation eddy-viscosity turbulence models for engineering applications," AIAA J., vol. 32, no. 8, pp. 1598-1605, 1994, doi: 10.2514/3.12149.

[22] F. R. Menter, "Review of the shear-stress transport turbulence model experience from an industrial perspective," Int. J. Comput. Fluid Dyn., vol. 23, no. 4, pp. 305-316, Apr. 2009, doi: 10.1080/10618560902773387.

[23] W. J. Kim, S. H. Van, and D. H. Kim, "Measurement of flows around modern commercial ship models," Exp. Fluids, vol. 31, no. 5, pp. 567-578, 2001, doi: 10.1007/s003480100332.

[24] ITTC, "Practical guidelines for ship CFD applications," presented at the Proceedings of 26th ITTC, Hague, 2011.

[25] S. Song, Y. K. Demirel, and M. Atlar, "An investigation into the effect of biofouling on the ship hydrodynamic characteristics using CFD," Ocean Eng., vol. 175, pp. 122-137, Mar. 2019, doi: 10.1016/j.oceaneng.2019.01.056.

[26] S. Sezen, A. Dogrul, C. Delen, and S. Bal, "Investigation of self-propulsion of DARPA Suboff by RANS method," Ocean Eng., vol. 150, pp. 258-271, 2018.

[27] Ishmail. B. Celik, U. Ghia, and P. J. Roache, "Procedure for estimation and reporting of uncertainty due to discretization in CFD applications," J. Fluids Eng.-Trans. ASME, vol. 130, no. 7, Jul. 2008, doi: 10.1115/1.2960953.

[28] Y. K. Demirel, O. Turan, and A. Incecik, "Predicting the effect of biofouling on ship resistance using CFD," Appl. Ocean Res., vol. 62, pp. 100-118, Jan. 2017, doi: 10.1016/j.apor.2016.12.003.

[29] D. Owen, Y. K. Demirel, E. Oguz, T. Tezdogan, and A. Incecik, "Investigating the effect of biofouling on propeller characteristics using CFD," Ocean Eng., vol. 159, pp. 505-516, Jul. 2018, doi: 10.1016/j.oceaneng.2018.01.087.

[30] S. Song, Y. K. Demirel, and M. Atlar, "An Investigation Into the Effect of Biofouling on Full-Scale Propeller Performance Using CFD," in Proceedings of the ASME 2019 38th International Conference on Ocean, Offshore and Arctic Engineering. Volume 2: CFD and FSI, Glasgow, Scotland, UK, 2019.

[31] S. Song, Y. K. Demirel, and M. Atlar, "Penalty of hull and propeller fouling on ship self-propulsion performance," Appl. Ocean Res., vol. 94, p. 102006, Jan. 2020, doi: 10.1016/j.apor.2019.102006. 
[32] S. Song, Y. K. Demirel, M. Atlar, S. Dai, S. Day, and O. Turan, "Validation of the CFD approach for modelling roughness effect on ship resistance," Ocean Eng., vol. 200, p. 107029, Mar. 2020, doi: 10.1016/j.oceaneng.2020.107029.

[33] M. Terziev, T. Tezdogan, and A. Incecik, "A geosim analysis of ship resistance decomposition and scale effects with the aid of CFD," Appl. Ocean Res., vol. 92, p. 101930, Nov. 2019, doi: 10.1016/j.apor.2019.101930.

[34] L. Larsson and H. C. Raven, The Principles of Naval Architecture Series: Ship Resistance and Flow. Jersey City, NJ: The Society of Naval Architects and Marine Engineers, 2010.

[35] K. E. Schoenherr, "Resistance of flat surfaces moving through a fluid," Trans Soc Nav Arch. Mar Eng, vol. 40, pp. 279-313, 1932. 